\title{
Side-directed transfer and presystemic metabolism of selenoneine in a human intestinal barrier model
}

Isabelle Rohn ${ }^{1 *}$, Nina Kroepfl ${ }^{2 *}$, Julia Bornhorst ${ }^{1,3,4}$, Doris Kuehnelt ${ }^{2}$, Tanja Schwerdtle ${ }^{1,3}$

\author{
${ }^{1}$ Institute of Nutritional Science, University of Potsdam, Nuthetal, Germany \\ ${ }^{2}$ Institute of Chemistry, Analytical Chemistry, NAWI Graz, University of Graz, Graz, Austria \\ ${ }^{3}$ TraceAge - DFG Research Unit FOR 2558, Berlin-Potsdam-Jena, Germany \\ ${ }^{4}$ Faculty of Mathematics and Natural Sciences, University of Wuppertal, Wuppertal, \\ Germany \\ *These authors contributed equally to the work.
}

Corresponding author address:

Institute of Nutritional Science, University of Potsdam, Arthur-Scheunert-Allee 114-116, 14558 Nuthetal, Germany, Phone: +49-33200/88-5528, Fax: +49-33200/88-5573, Email: tanja.schwerdtle@uni-potsdam.de

\begin{abstract}
Abbreviations:
HR-ESI-MS, high resolution electrospray ionisation mass spectrometry; ICPMS, inductively coupled plasma mass spectrometry; MeSeCys, Se-methylselenocysteine; MWCO, molecular weight cut-off filtration; TEER, transepithelial electrical resistance
\end{abstract}

\section{Keywords:}

Bioavailability / Caco-2 intestinal barrier model / Presystemic metabolism / Selenoneine / Semethylselenoneine 


\section{Abstract}

Scope: Selenoneine, a recently discovered selenium (Se) species mainly present in marine fish, is the Se analogue of ergothioneine, a sulfur-containing purported antioxidant. Although similar properties have been proposed for selenoneine, data on its relevance to human health are yet scarce. Here, we investigated the transfer and presystemic metabolism of selenoneine in an in vitro model of the human intestinal barrier.

Methods and results: Selenoneine and the reference species Se-methylselenocysteine (MeSeCys) and selenite were applied to the Caco-2 intestinal barrier model. Selenoneine was transferred in higher amounts, but with similar kinetics as selenite, while MeSeCys showed the highest permeability. In contrast to the reference species, transfer of selenoneine was directed towards the blood side. Cellular Se contents demonstrate that selenoneine was efficiently taken up by Caco-2 cells. Moreover, HPLC/MS based Se speciation studies revealed a partial metabolism to Se-methylselenoneine, a metabolite previously detected in human blood and urine.

Conclusions: Selenoneine is likely to pass the intestinal barrier via transcellular, carriermediated transport, is highly bioavailable to Caco-2 cells and undergoes metabolic transformations. Therefore, further studies are needed to elucidate its possible health effects and to characterize the metabolism of selenoneine in humans. 


\section{Introduction}

Selenium (Se) is an essential trace element involved in a multitude of physiological processes in animals and humans ${ }^{[1]}$ It is taken up almost exclusively through the diet, and various chemical species of Se are present in plant- and animal-based food products. Moreover, it is commonly used in nutritional supplements, as health-promoting effects have been linked to additional Se supplementation. However, elevated uptake may have toxic effects. ${ }^{[2,3]}$ Apart from dosage and baseline status, the administered Se species and their metabolism are key determinants for subsequent health impacts. ${ }^{[4]}$ Disparities arising from the structure of the Se species are reflected by their differing bioavailability and toxicity, but also possible beneficial effects are highly species-dependent.

In this light, the identification of the naturally occurring Se species selenoneine (2-selenyl- $\mathrm{N}_{\alpha}$, $\mathrm{N}_{\alpha}, \mathrm{N}_{\alpha}$-trimethyl-L-histidine $)^{[5]}$ was encountered with great interest. Being the Se analogue of ergothioneine, a sulfur species with putative antioxidant properties, ${ }^{[6]}$ similar attributes have been proposed for selenoneine. An initial study reported that selenoneine possessed greater antioxidant activity against 1,1-diphenyl-2-picrylhydrazyl in a spectrophotometric radicalscavenging assay than ergothioneine..$^{[5]}$ Moreover, a potential role in methyl mercury detoxification has been suggested in zebrafish embryos and dolphin liver. ${ }^{[7,8]}$ Apart from these pilot studies, knowledge about the biological effects of selenoneine is limited, which is mainly due to the fact that the pure species has not been available in sufficient quantities. After its first identification in tuna, where it constitutes the major water-extractable Se species in muscle and blood, ${ }^{[5]}$ significant amounts of selenoneine were found in other marine fish species, and smaller quantities in terrestrial animals. ${ }^{[5,9]}$ Moreover, selenoneine as well as its methylated metabolite Se-methylselenoneine have been detected in human blood. ${ }^{[10-12]}$ Consequently, selenoneine is bioavailable to humans and seems to undergo metabolic transformations. However, no information about absorption efficiencies and mechanisms as well as places of metabolism are available to date, and physiological effects of selenoneine and its metabolite 
are yet unclear. Considering its nutritional relevance and at the same time unknown impact on human health, a comprehensive characterization of selenoneine is indispensable.

Following the successful biosynthesis and isolation of selenoneine from genetically modified fission yeast Schizosaccharomyces pombe ${ }^{[13]}$ sufficient quantities of the pure species were obtained to assess its toxicological, metabolic and putative protective properties in vitro. As an initial step and basis for further in vitro characterization, the current study aimed to assess the intestinal bioavailability and metabolism of selenoneine using the Caco-2 intestinal barrier model. This well established and widely used in vitro model mimics the human intestinal barrier. Here, we provide data regarding the toxicity of selenoneine, its impact on the integrity of and its transfer across the intestinal barrier in comparison to the well-characterized reference species Se-methylselenocysteine (MeSeCys) and selenite. Furthermore, we investigated the type of transport, the cellular bioavailability as well as the presystemic metabolism of selenoneine in Caco-2 cells.

\section{Experimental Section}

\subsection{Materials, chemicals and reagents}

Water applied in the experiments was always purified using a water purification system (10 $\mathrm{M} \Omega \mathrm{cm}$, Elix 15, Merck KGaA, Darmstadt, Germany; or $18.2 \mathrm{M} \Omega \mathrm{cm}$, Milli-Q, Academic water purification system, Merck Millipore $\mathrm{GmbH}$, Vienna, Austria). Caco-2 cells were purchased from the European Collection of Cell Cultures (ECACC; number 86010202, Salisbury, UK). Minimum essential medium Eagle (MEM), non-essential amino acids and fetal calf serum were obtained from Biochrom (Berlin, Germany). Penicillin/streptomycin solutions and trypsin were products of Sigma-Aldrich (Steinheim, Germany). Culture dishes were from TPP (Trasadingen, Switzerland) and Transwell filters were from Corning (Wiesbaden, Germany). The neutral red dye was purchased from Roth $\mathrm{GmbH}+\mathrm{Co}$. KG (Karlsruhe, Germany) and the cell-counting kit-8 (CCK-8) from Dojindo molecular technologies (Munich, Germany). Sodium selenite 
$\left(\mathrm{Na}_{2} \mathrm{SeO}_{3} \cdot 5 \mathrm{H}_{2} \mathrm{O}, \geq 99 \%\right)$ was supplied from Sigma-Aldrich and L-MeSeCys (>98\%) was from Abcam (Cambridge, UK). Selenoneine was isolated from genetically modified fission yeast Schizosaccharomyces pombe at the University of Graz, Institute of Chemistry, Analytical Chemistry, with data on its identity and purity published elsewhere. ${ }^{[13]}$ Nitric acid $(65 \%$, suprapur) and the natural elemental Se standard $\left(1 \mathrm{~g} \mathrm{~L}^{-1}\right)$ were supplied by Merck (Darmstadt, Germany). Isotopically enriched ${ }^{77}$ Se was purchased from Eurisotop SAS (Saarbrücken, Germany). Isopropanol (>99.999\%) was from Sigma-Aldrich and Bradford solution was from Bio-Rad (Munich, Germany). All other chemicals were of p.a. grade and were from Merck or Sigma-Aldrich.

For the preparation of solutions for Se speciation analysis analytical grade chemicals were used throughout. Ammonium formate $(\geq 95 \%)$, formic acid $(\geq 98 \%$, p.a. $)$, tris-(2carboxyethyl)phosphine hydrochloride (TCEP, >98\%, for biochemistry) and ammonia solution ( $\geq 25 \%$, p.a.) were obtained from Carl Roth $\mathrm{GmbH}+$ Co. KG. Malonic acid (99\%) and methanol (HPLC gradient grade) were purchased from Sigma-Aldrich and VWR International (Fontenaysous-Bois, France), respectively. Preparation of the mobile phases for HPLC separations of Se species was performed by dissolving the appropriate amount of ammonium formate or malonic acid in water, adding the required amount of methanol and adjusting the $\mathrm{pH}$ with formic acid or ammonia solution. Sodium selenite was purchased from Merck, sodium selenate and D, L-selenomethionine (>99\%) were obtained from Fluka (Buchs, St. Gallen, Switzerland), and MeSeCys was purchased from Sigma-Aldrich. As previously reported, Se-methylselenoneine was extracted and purified from fresh tuna muscle ${ }^{[14]}$ and selenoneine was isolated from Schizosaccharomyces pombe. ${ }^{[13]}$ Se standard solutions for calibration were prepared by dilution of aqueous stock standard solutions of the respective Se compound in water.

For total Se determination in the cell culture media and lysates from the culture dish experiments concentrated nitric acid (65\%, p.a.; Carl Roth $\mathrm{GmbH}+$ Co. $\mathrm{KG}$ ) was further purified by sub-boiling distillation. Single element standard solutions of Se (1000 mg Se $\mathrm{L}^{-1} \pm$ 
$0.2 \%$ in $\left.2 \% \mathrm{HNO}_{3}\right)$ and germanium $\left(1000 \mathrm{mg} \mathrm{Ge} \mathrm{L}^{-1}\right.$ in $2 \% \mathrm{HNO}_{3}$ and $0.5 \% \mathrm{HF}$ ) for total Se determination by ICPMS were purchased from Carl Roth $\mathrm{GmbH}+$ Co. KG.

\subsection{Cell culture and incubation with Se species}

Caco-2 cells were cultivated as previously reported. ${ }^{[15]}$ Briefly, cells were thawed in passage

5 number 50 and sub-cultured three times to achieve a stable phenotype. For all experiments, cells were seeded at a density of $5 \times 10^{4}$ cells per $\mathrm{cm}^{2}$ and cultured for 11 days until complete differentiation. The culture medium was renewed every $2-3$ days during this time.

Stock solutions $(10-100 \mathrm{mM})$ of the Se species were prepared and diluted in purified water. Selenite and MeSeCys stock solutions were freshly prepared for each experiment, while aliquots of the selenoneine stock solution were stored at $-80^{\circ} \mathrm{C}$ and thawed and diluted shortly before each use.

\subsection{Dosage information / Dosage regimen}

Differentiated Caco-2 cells were incubated with 0.5 to $100 \mu \mathrm{M}$ selenoneine, selenite or LMeSeCys for $72 \mathrm{~h}$. Se transfer and speciation studies were carried out with $0.5-10 \mu \mathrm{M}$ of the

Se species. These supraphysiological doses were chosen to ensure analytical determination and to study the transfer and presystemic metabolism of the Se species mechanistically. Cytotoxicity was tested up to $100 \mu \mathrm{M}$ as described in Section 2.3, and subsequently, non-toxic concentrations were used for transfer and speciation studies.

\subsection{Cytotoxicity testing}

The neutral red uptake assay and the CCK-8 assay were employed to assess the impact of the Se species on lysosomal integrity and cellular dehydrogenase activity, respectively. These are used as viability markers to evaluate the cytotoxicity of the Se species. Both assays were carried out in differentiated Caco-2 cells as described previously. ${ }^{[15]}$ 


\subsection{Evaluation of monolayer and barrier integrity by TEER and capacitance measurement}

The human intestinal cell line Caco- 2 is widely used as an in vitro model to study the transfer of species across the intestinal barrier ${ }^{[16-18]}$ and has been applied before to evaluate the

5 transfer of Se species. ${ }^{[19-23]}$ Basically, Caco-2 cells are grown as a monolayer on Transwell filter inserts, resembling the intestinal barrier and separating two compartments of cell medium. The upper (apical) compartment corresponds to the intestinal lumen, whereas the lower (basolateral) chamber represents the blood side. Experiments were carried out as previously reported. ${ }^{[15]}$ Briefly, Caco-2 cells were seeded on Transwell filters with microporous polycarbonate membranes $\left(1.12 \mathrm{~cm}^{2}\right.$ growth area, $0.4 \mu \mathrm{m}$ pore size $) .0 .5 \mathrm{~mL}$ culture medium was added to the apical compartment and $1 \mathrm{~mL}$ to the basolateral compartment. 11 days after seeding, cells were exposed to the Se species by incubation into the apical compartment (intestinal lumen) and/or basolateral compartment (portal vein).

The barrier integrity of the Caco-2 monolayer was monitored continuously throughout the experiment using a cellZscope device (nanoAnalytics, Münster, Germany), enabling automatic measurements of the transepithelial electrical resistance (TEER) and capacitance. The TEER is proportional to the tightness of a barrier, whereas the electrical capacitance is proportional to the plasma membrane surface area, thereby providing additional information about the cell layer properties.

2.6 Transfer across the Caco-2 intestinal barrier model and cellular total Se concentrations

To study the transfer of Se species across the in vitro intestinal barrier, aliquots of cell medium were taken from the apical and basolateral compartment after $0,8,24,48$ and $72 \mathrm{~h}$ of incubation. Total Se was determined with an ICP-QQQ-MS 8800 system (Agilent, Waldbronn, Germany) applying a validated isotope dilution method developed by Marschall et al., with a limit of quantification (LOQ) of $0.032 \mu \mathrm{g}$ Se per L. ${ }^{[24]}$ The medium aliquots were diluted with 
nitric acid and ${ }^{77} \mathrm{Se}$ in order to obtain a solution with $3 \mu \mathrm{g}{ }^{77} \mathrm{Se} \mathrm{L}^{-1}$ and $2 \% \mathrm{HNO}_{3}$. Cellular total Se contents were measured after $72 \mathrm{~h}$ of incubation at the end of each experiment. After complete removal of the remaining medium, the filter membranes with the Caco-2 monolayers were cut out and washed with ice-cold phosphate buffered saline (PBS). Then, cells were lysed from the filters by adding $300 \mu \mathrm{L}$ RIPA buffer (10 mM TRIS, $150 \mathrm{mM} \mathrm{NaCl}, 1 \mathrm{mM}$ EDTA, $1 \%$ Triton $\mathrm{X}-100,1 \%$ sodium deoxycholate, $0.1 \% \mathrm{SDS})$. Following incubation (15 $\mathrm{min}, 4^{\circ} \mathrm{C}$ ) and centrifugation $\left(10000 \times \mathrm{g}, 20 \mathrm{~min}, 4^{\circ} \mathrm{C}\right)$, the lysates were obtained and diluted for Se quantification as mentioned above. An aliquot of each lysate was used to determine the protein content for standardization, applying the Bradford assay. ${ }^{[25]}$ Before ICP-QQQ-MS analysis, 3\% isopropanol were added to all samples for sensitivity enhancement. ${ }^{[26]}$

\subsection{Experiments in culture dishes}

\subsubsection{Samples and sample preparation}

Due to the low number of cells used and the low Se concentrations applied in the barrier studies, additional experiments were carried out in culture dishes for the biotransformation studies. Caco-2 cells were cultivated as stated in 2.2. Briefly, on day 11 cells were exposed to the respective Se species $(0.5 \mu \mathrm{M}$ selenoneine; $1 \mu \mathrm{M}$ selenoneine, selenite, or MeSeCys $)$ for $72 \mathrm{~h}$. Aliquots of the cell culture medium were taken after $5 \mathrm{~min}$ and $8 \mathrm{~h}$ of incubation. After 72 $\mathrm{h}$, the remaining medium was collected. Cells were trypsinized, washed twice with ice-cold PBS and cell pellets were obtained by centrifugation. Cell culture media and cell pellets were prepared in Potsdam, shipped to Graz on dry ice and stored at $-80^{\circ} \mathrm{C}$ until analysis.

Cell lysates were prepared by adding $300 \mu \mathrm{L}$ of water to the cell pellets, mixing, and resting for 20 min on ice, followed by sonication ( 5 manually induced pulses of $3 \mathrm{sec}$ with amplitudes of 1 time each $20 \%, 30 \%$, and $40 \%$ as well as 2 times $50 \%$; Branson SFX 250 Sonifier, Branson Ultrasonics Corporation, Danbury, Connecticut, USA). After cell lysis, cell samples from the culture dishes were centrifuged ( 3 times $10 \mathrm{~min}, 21400 \times \mathrm{g}, 4^{\circ} \mathrm{C}$; D3024R High Speed Refrigerated Micro-Centrifuge, SCILOGEX, LLC., Rocky Hill, Connecticut, USA). After 
centrifugation, $50 \mu \mathrm{L}$ of the supernatants were directly analyzed by HPLC/ICPMS, while $100 \mu \mathrm{L}$ were subjected to MWCO filtration $\left(3000 \mathrm{Da} ; 60 \mathrm{~min}, 15000 \times \mathrm{g}, 4^{\circ} \mathrm{C}\right.$; Vivaspin 500 cut-off filters, Sartorius, Stonehouse, Gloucestershire, UK) before analysis.

\subsubsection{Determination of total Se}

5 Microwave-assisted acid digestion of cell culture media and cell lysates from the culture dishes was performed in an UltraClave IV High Performance Microwave Reactor (MLS GmbH, Leutkirch, Germany). For this purpose, $50 \mu \mathrm{L}$ of syringe filtered cell culture media or $10 \mu \mathrm{L}$ of cell pellet lysates were homogenized with $2 \mathrm{~mL}$ water and $1 \mathrm{~mL}$ concentrated nitric acid and digested as previously reported. ${ }^{[27]}$ An internal standard solution $\left(\mathrm{Ge}\right.$ in $\left.2 \% \mathrm{HNO}_{3}\right)$ was added to the digests before ICPMS analysis (final concentration $25 \mu \mathrm{g} \mathrm{L}^{-1}$ ). Total Se was determined by ICPMS (Agilent 7900, hydrogen mode: $3.5 \mathrm{~mL} \mathrm{H}_{2} \mathrm{~min}^{-1}$ ) on $\mathrm{m} / \mathrm{z} 78$ using external calibration. ${ }^{[13]}$ For quality control an aqueous standard solution of selenomethionine (400 mg Se $L^{-1}$ ) was digested together with the samples and total Se was determined by ICPMS (Recovery $104 \pm 1 \%$ ).

\subsection{Speciation analysis}

\subsubsection{Samples and sample preparation}

Se speciation analysis was performed on culture media and cell lysates from the Caco-2 intestinal barrier model treated with $0.5,1$, or $10 \mu \mathrm{M}$ selenoneine (incubation either apical, basolateral, or from both sides), or with $10 \mu \mathrm{M}$ selenite (apical incubation). Cell culture media and cell lysates were prepared in Potsdam, shipped to Graz on dry ice and stored at $-80^{\circ} \mathrm{C}$ until analysis. Furthermore, cell lysates and media from the culture dish experiments (incubation with $1 \mu \mathrm{M}$ selenite or MeSeCys, as well as 0.5 or $1 \mu \mathrm{M}$ selenoneine; see above) were investigated.

Cell culture media were filtered through syringe filters $(0.20 \mu \mathrm{M}$, membrane: polyamide (nylon); Chromafil $^{\circledR}$ Xtra PA-20/13, Macherey-Nagel GmbH \& Co. KG, Düren, Germany) and either diluted with water or directly subjected to HPLC/ICPMS analysis. Molecular weight cut-off 
filtration (MWCO 3000 Da, Vivaspin 500 cut-off filters) was performed on cell lysates by centrifugation for $60 \mathrm{~min}$ at $4^{\circ} \mathrm{C}$ and $15000 \times \mathrm{g}$. In selected cases, MWCO filtration was also applied to cell culture media.

\subsubsection{Determination of Se species by HPLC/ICPMS and HPLC/Orbitrap-MS}

5 Quantitative determination of Se species was performed by HPLC/ICPMS. An Agilent 1100 HPLC system including a degasser (G1379A), a binary pump (G1312A), a thermostated autosampler (G1330A) and a thermostated column compartment (G1316A) was connected via PEEK capillary tubing (i.d. $0.125 \mathrm{~mm})$ to an Agilent 7900 ICPMS operated in $\mathrm{H}_{2}$-mode $\left(\mathrm{H}_{2}\right.$ flow rate: $3.5 \mathrm{~mL} \mathrm{~min}^{-1}$ ) and equipped with a Micro Mist nebulizer and a Scott-type spray chamber. The signals at $m / z 77,78,80$, and 82 were monitored and $m / z 78$ was used for quantification against aqueous standard solutions of selenite and selenate (for samples treated with selenite), as well as MeSeCys and selenomethionine (for samples treated with MeSeCys and selenoneine). Signal enhancement was achieved by using $1 \% \mathrm{CO}_{2}$ in $\mathrm{Ar}$ as optional gas at a flow rate of $12 \%$ of the carrier gas flow when HPLC separation was performed without organic solvent in the mobile phase. All culture media and cell lysates were analyzed by reversedphase HPLC using a Waters Atlantis ${ }^{\circledR} \mathrm{dC} 18(4.6 \times 150 \mathrm{~mm})$ column (chromatographic condition I, Supporting Information Table S1). Media and lysates of cell pellets treated with sodium selenite were additionally subjected to anion-exchange chromatography using a Dionex IonPac ${ }^{\mathrm{TM}}$ AS14-A $(3 \times 150 \mathrm{~mm})$ column with isocratic elution (chromatographic conditions II, Supporting Information Table S1). The injection volume was $10 \mu \mathrm{L}$.

Se species were identified by HPLC/Orbitrap-MS under chromatographic condition I (Supporting Information Table S1) using a Dionex Ultimate 3000 HPLC system (Thermo Scientific, Waltham, USA) consisting of a Rapid Separation (RS) pump, an RS autosampler and an RS column compartment coupled to a Q Exactive Orbitrap Mass Spectrometer (Thermo Scientific) equipped with a heated electrospray ionization (HESI) source. The following source settings were used to operate the electrospray ionization source in positive mode: gas temperature $500^{\circ} \mathrm{C}$, gas flow rates 65 (sheath) and 20 (aux) instrument units, spray voltage 
$3500 \mathrm{~V}$ and capillary temperature $300^{\circ} \mathrm{C}$. The resolution for a full scan range of $\mathrm{m} / \mathrm{z} 250-350$ was 70,000 (full width half maximum, FWHM). For the automatic gain control (AGC) target and the maximum injection time (IT) $3 \times 10^{6}$ and 100 ms were used, respectively. Further structural information on the precursor ion at $m / z 292.056$ was gained by MS/MS (ddMS/MS), which was performed with collision energies of $10,20,30$ (stepped) instrument units. MS/MS settings were the following: resolution 17,500 FWHM, maximum IT $50 \mathrm{~ms}$, AGC target $1 \times 10^{5}$ and isolation window 8 Thomson (mass/charge).

\subsection{Statistics}

The presented results were obtained with at least two independent Caco- 2 passages. The cytotoxicity tests for each concentration were conducted in triplicates $(n \geq 6)$ and the barrier studies for each concentration were performed in duplicates $(n \geq 4)$. All experiments were carried out independently at least two times. Histograms were created using GraphPad Prism (GraphPad Software Inc.). Data presented in the figures and tables are given as mean values with SD. Cytotoxicity and bioavailability data were analyzed using one-way ANOVA followed by Dunnett's multiple comparison post-hoc tests. For both-sided incubations, unpaired $t$-tests were used to test for accumulation in one compartment. Significance levels are ${ }^{*} p<0.05,{ }^{* *} p$ $<0.01$, and ${ }^{* * *} p<0.001$.

\section{$\underline{3 \text { Results }}$}

In this study, the transfer and presystemic metabolism of selenoneine in comparison to the reference species selenite and MeSeCys (Fig. 1) were assessed using the Caco-2 intestinal barrier model. Furthermore, cytotoxicity and cellular uptake of these Se species as well as their impact on the integrity of the intestinal barrier were studied.

\subsection{Impact of the Se species on barrier integrity and viability of Caco-2 cells}

As a first step, the cytotoxic potential of the Se species was assessed after $72 \mathrm{~h}$ of incubation in differentiated Caco-2 cells. Hence, the cell viability markers lysosomal integrity and 
dehydrogenase activity were measured applying the neutral red uptake assay and the CCK-8 assay, respectively. For both endpoints, no cytotoxic effects of selenoneine were observed in the tested concentration range up to $100 \mu \mathrm{M}$ (Fig. 2). In contrast, selenite substantially affected both viability markers, which is reflected by the concentration values that reduce the cell viability by $30 \%\left(\mathrm{EC}_{30}\right)$ of both assays (Table 1). MeSeCys had no impact on dehydrogenase activity, but impaired lysosomal integrity at very high concentrations (> $100 \mu \mathrm{M}$, Table 1).

As an intact barrier is a prerequisite for transfer studies, barrier integrity has to be ensured and cytotoxic effects should be avoided. Therefore, barrier studies were carried out with subcytotoxic concentrations applying a maximum of $10 \mu \mathrm{M}$ of the Se species. The online measurement of both, TEER (Fig. 3 A, C and E) and electrical capacitance (Fig. 3 B, D and F), confirmed an intact barrier after apical incubation with 1 and $10 \mu \mathrm{M}$ of selenite (Fig. $3 \mathrm{~A}$ and B), 1 and $10 \mu \mathrm{M}$ of MeSeCys (Fig. $3 \mathrm{C}$ and D) as well as $0.5,1$, and $10 \mu \mathrm{M}$ of selenoneine (Fig. $3 \mathrm{E}$ and F). Furthermore, incubation of these Se species concentrations in the basolateral compartment or parallel incubation in both compartments did also not affect the barrier integrity (data not shown). The TEER values did not decrease below $1000 \Omega \mathrm{cm}^{2}$ and capacitance values were between 3.5 and $4.0 \mu \mathrm{F} / \mathrm{cm}^{2}$, ensuring a confluent monolayer. ${ }^{[15]}$

\subsection{Transfer of selenite, MeSeCys and selenoneine across the Caco-2 barrier after apical incubation and cellular Se concentrations}

To characterize the intestinal bioavailability of the test substances, the time-dependent crossover of Se was studied after incubation of the Se species in the apical compartment, thus mimicking an influx from the intestinal lumen to the blood side. As selenoneine is most stable in its oxidized, dimeric form, ${ }^{[5]}$ (see also Fig.1) and was isolated and purified as such, ${ }^{[13]}$ we decided to apply $0.5 \mu \mathrm{M}$ selenoneine in comparison to $1 \mu \mathrm{M}$ of selenite and $1 \mu \mathrm{M}$ of MeSeCys to use equivalent amounts of Se. As shown in Fig. 4, all investigated Se species were transferred across the barrier, but with varying efficiencies and quantities. The crossover of selenite (Fig. 4 A) occurred to the lowest extent and rather slowly, with detectable Se concentrations in the basolateral compartment only after $24 \mathrm{~h}$. In contrast, MeSeCys passed 
the intestinal barrier faster and more efficiently, thereby reaching comparable concentrations in both compartments after $72 \mathrm{~h}$ (Fig. 4 B). Selenoneine displayed a crossover behaviour similar to that of selenite, but was transferred to a greater extent (Fig. 4 C). Taking a closer look, the Se concentration in the apical compartment decreased more rapidly and to a greater degree after apical incubation with selenoneine than after apical incubation with selenite. However, in the basolateral compartment, increased Se concentrations were measured only after $24 \mathrm{~h}$ for both Se species. This indicates that selenoneine might be taken up or retained more efficiently by Caco-2 cells than selenite. To clarify this, cellular total Se concentrations were determined after lysis of the barrier forming cells at the end of each transfer experiment. Increased cellular Se contents were measured after $72 \mathrm{~h}$ of incubation with selenite and selenoneine from the apical side (Table 2). However, selenoneine displayed a significantly higher cellular bioavailability, with $7-9 \%$ of the initial incubated Se amount present within the cell lysates. In case of selenite, only $1-2 \%$ of the applied Se amount were quantified in the Caco-2 cell layers. Cellular Se contents after incubation with MeSeCys were indistinguishable from untreated control cells. Barrier studies carried out with higher concentrations (up to 10 $\mu \mathrm{M})$ showed similar results regarding transfer (Supporting Information Fig. S1) and cellular bioavailability (Supporting Information Table S2) of the applied Se species.

\subsection{Simultaneous incubation in both compartments}

In the next step, we aimed to investigate the transfer process of the Se species in more detail, to see if the transfer was heading for one direction or occurred in a non-directional manner. Hence, the Se species were incubated simultaneously in equal concentrations in the apical and basolateral compartment. As no accumulation to either side was observed within $72 \mathrm{~h}$ of incubation with $1 \mu \mathrm{M}$ selenite or MeSeCys (Fig. $5 \mathrm{~A}$ and B), the transfer of these Se species appeared to be non-directional. In contrast, for selenoneine, a clear enrichment $(P=0.013)$ in the basolateral compartment occurred (Fig. $5 \mathrm{C}$ ), indicating a side-directed transfer of this species from the intestinal lumen to the blood. This was further supported by the results from a third experimental approach, in which the incubation of selenoneine in the basolateral 
compartment only resulted in hardly any transfer from the basolateral to the apical side (data not shown).

\subsection{Metabolism of selenite, MeSeCys and selenoneine by Caco-2 cells}

As biotransformation of the reference species selenite and MeSeCys in Caco-2 cells has been studied before ${ }^{21}$ it will only be discussed briefly and emphasis will be put on the metabolism of selenoneine, which has not been investigated yet due to the lack of the pure species.

Results for Caco-2 cells incubated with $1 \mu \mathrm{M}$ Se in the form of MeSeCys in culture dishes showed that about $90 \%$ of the total Se in the medium was present in this form after 5 min and $8 \mathrm{~h}$, which is in accordance with literature data from experiments in the intestinal barrier model conducted for 2 h. ${ }^{21}$ After 72 h, about $60 \%$ of the total Se in the medium and about $3 \%$ of the total Se in the cell lysate were in the form of MeSeCys. Several unknown Se species were detected in the cell culture media as well as cell lysates. Based on results reported in the literature ${ }^{21}$ and experiments using MWCO filtration it was assumed that they were mainly Secontaining proteins. These unknown species were not further investigated.

Similarly, the originally applied species as well as unknown Se species, which were again suspected to correspond to protein bound Se and, hence, not further investigated, were detected in culture media and cell lysates from Caco-2 cells after incubation with selenite. In the transfer experiments, selenite concentrations in the basolateral compartment corresponded to about $40 \%$ of the total Se and were about 30 times lower than those on the apical side (selenite representing ca. $90 \%$ of the total Se) where incubation was performed. This result was in agreement with previous findings, ${ }^{[22]}$ even though it was suggested by Gammelgaard et al. that selenite is not transported through the Caco-2 monolayer in its inorganic form. ${ }^{[21]}$ An explanation for this disagreement would be the duration of the experiments. As shown in Fig. $4 \mathrm{~A}$ an increase in the Se concentration on the basolateral side of the barrier only occurred after incubation times above $24 \mathrm{~h}$. However, a maximum incubation time of $2 \mathrm{~h}$ was used in the aforementioned study, ${ }^{[21]}$ which might have, therefore, not detected a transfer of selenite from the apical to the basolateral side. 
Selenoneine was the dominating Se species (ca. $90 \%$ of total Se, Supporting Information Table S3) in culture media and lysates of Caco-2 cells incubated in culture dishes with 0.5 or $1 \mu \mathrm{M}$ selenoneine for 72 h. A minor unknown Se species (retention time: ca. $3.7 \mathrm{~min}$ ) was detected before MWCO filtration in the cell lysates (Fig. 6). It is to note that selenoneine was also reduced by approximately $20 \%$ when MWCO filtration was employed to the cell lysates. However, the reduction in analyte was even more pronounced in the case of the unknown (Fig. 6), suggesting that it possesses a molecular mass larger than $3000 \mathrm{Da}$ or is partially attached to larger molecules like proteins retained by the MWCO filter. Even though identification of the unknown species by HPLC/HR-ESI-MS was not successful, its presence also in the lysates of cells incubated with MeSeCys or selenite (data not shown) suggested that its formation was not dependent on the Se substrate provided to the Caco-2 cells.

Besides this unknown species, a peak that was not baseline resolved from selenoneine was detected at its high retention time side in HPLC/ICPMS (Fig. 6), hinting towards the formation of another metabolite specific for selenoneine. HPLC/HR-ESI-MS confirmed the presence of Se-methylselenoneine (Fig. 7), a metabolite of selenoneine recently discovered in human blood and urine. ${ }^{[11,12]}$ Besides being present in the cell lysates, Se-methylselenoneine could not be unambiguously identified in the culture dish media after 5 min or $8 \mathrm{~h}$ of incubation with selenoneine, but was clearly detectable after $72 \mathrm{~h}$ of treatment (Supporting Information Fig. S2), confirming its formation from selenoneine.

In media and cell lysates obtained from the Transwell experiments selenoneine accounted for about $80-110 \%$ of the total Se in the media and $55-90 \%$ in the cell lysates (Table 3). To investigate a potential underestimation of the concentration of selenoneine due to its binding to thiol groups, $0.1 \mathrm{mM}$ tris(2-carboxyethyl)phosphine (TCEP) was added to the reversedphase mobile phase (chromatographic condition I, Supporting Information Table 1) as a reducing agent, as previously tested. ${ }^{[12,13]}$ Results obtained with TCEP in the mobile phase did, however, not differ significantly from the results obtained without it, indicating that selenoneine was not bound to other matrix-components to a larger extent (data not shown). 
Therefore, the major Se species in all three compartments (cell lysates, medium from apical, and basolateral side) was the originally applied Se species provided to the cells.

Based on the results from the culture dish experiments, culture media and cell lysates obtained in the transfer studies were specifically investigated for the presence of Se-methylselenoneine by HPLC/HR-ESI-MS. Interestingly, clear signals for Se-methylselenoneine were detected in all cell lysates and culture media after apical or concurrent apical and basolateral application of selenoneine, whereas signals after basolateral application only were low and unambiguous identification of Se-methylselenoneine was not possible. This suggests that methylation of selenoneine occurs, when it is applied on the apical side. Hence, besides showing a directed transport of selenoneine in the intestinal barrier model from the apical to the basolateral side, methylation of selenoneine also was found to occur after apical incubation. Similar results have been reported for the methylated metabolites of flavonoids present in green tea. ${ }^{[28]}$ Even though qualitative analysis by HPLC/HR-ESI-MS showed the presence of Se-methylselenoneine in the samples obtained in the Transwell experiments, quantification by HPLC/ICPMS was not feasible due to the close structural resemblance of Se-methylselenoneine to selenoneine resulting in a similar chromatographic behaviour and lack of baseline separation of the two species (Fig. 6).

Besides selenoneine and Se-methylselenoneine most of the apical media showed an - albeit very minor - unknown peak which did not disappear after MCWO filtration (retention time ca. 22 min, Supporting Information Fig. 3), when incubation with selenoneine was performed on the apical side or on both sides. A further increase in the selenoneine concentration used for incubation from $1 \mu \mathrm{M}$ to $10 \mu \mathrm{M}$ lead to the detection of additional unknown metabolites, with the most intense ones appearing at retention times of 15 and 18 min (Supporting Information Fig. 4). However, none of these unknown metabolites could be identified by HPLC/HR-ESIMS. 


\section{Discussion}

The recently discovered Se species selenoneine is the predominant form of organic Se in tuna, swordfish and other fish species and therefore constitutes an important source of dietary Se, especially in countries with a high fish consumption. ${ }^{[5,10]}$ Both, selenoneine and its methylated metabolite Se-methylselenoneine have been detected in human blood, while only the methylated form was found in urine, indicating that selenoneine is metabolized and Semethylselenoneine is the excretory form. ${ }^{[11]}$ However, comprehensive approaches to unravel their roles in human Se metabolism and gain insight into possible health effects are lacking to date. In the present study, we assessed the intestinal bioavailability of selenoneine in relation to selenite and MeSeCys, as well as its presystemic metabolism in the well characterized in vitro Caco-2 intestinal barrier model.

Selenoneine exerted no cytotoxic effects in differentiated Caco-2 cells. Although it has been suggested that selenoneine might be a non-toxic antioxidant, ${ }^{[29]}$ no cytotoxicity data have been available yet. The reference species selenite and MeSeCys have been investigated before in Caco-2 cells, ${ }^{[19-23]}$ however, only one of these studies provided cytotoxicity data. Here, exposure of the cells for $6 \mathrm{~h}$ with selenite concentrations higher than $100 \mu \mathrm{M}$ significantly reduced cell viability, while MeSeCys was non-toxic. ${ }^{[23]}$ In agreement with other in vitro and rodent studies, selenite displayed considerably higher cytotoxicity compared to organic Se species. e.g.[30-33] However, Caco-2 cells were less sensitive compared to proliferating liver (HepG2), urothelial (UROtsa) and astrocytoma (CCF-STTG-1) cells, ${ }^{[30]}$ which is most likely due to the cells' differentiation status. In addition to the viability markers, TEER and electrical capacitance of the cell layer were monitored online, to ensure barrier integrity throughout the transfer studies.

Following incubation with the Se species in the apical lumen-facing compartment, a significant transfer of Se to the blood side was measured. Selenite displayed the lowest permeability, with a transfer of about $10 \%$ of the applied Se concentration. In contrast, MeSeCys passed the intestinal barrier faster and to a greater extent, thereby reaching comparable concentrations in 
both compartments after $72 \mathrm{~h}$. The kinetics of selenoneine transfer were comparable to those of selenite, however, a slightly higher transfer amount was obtained for the organic species. The results for selenite and MeSeCys are in line with previous studies using the Caco-2 model, all of which reported a faster and more efficient crossover of the amino acid analogue. ${ }^{[20-23]}$ Based on existing data, absorption of selenite is generally believed to occur via passive diffusion and preferentially via the paracellular route. ${ }^{[19,20,22,34]}$ For MeSeCys, a transcellular, carrier-mediated pathway via amino acid transporters has been suggested, ${ }^{[20-23,35]}$ and competition with the sulfur analogues has indicated a common transport system. ${ }^{[22,23]}$ The transfer data obtained in this study for the crossover of selenite and MeSeCys from the luminal to the blood side corroborate these earlier studies. In addition, the results obtained by simultaneous incubation in both compartments indicated a non-directional transfer of selenite and MeSeCys, thereby further supporting the previous view. However, as elevated Se contents following selenite exposure have been measured in Caco-2 cells, a fraction of selenite seems to be taken up by the cells. This might suggest that both, transcellular and paracellular diffusion, could be involved. Beyond that, the utilization of selenite to cover the cells' own Se supply is conceivable. In contrast, cellular retention of MeSeCys was negligible, which is in line with a previous study in the Caco-2 model. ${ }^{[22]}$ However, others have reported that Caco-2 cells accumulate Se from MeSeCys to a similar or slightly greater extent as from selenite. ${ }^{[20,21]}$ These divergences may arise from the heterogeneity of Caco-2 cell populations depending on the cell stock, passage number, cultivation conditions and differentiation period, resulting, among other things, in differential transporter expression profiles. ${ }^{[36]}$ In the present study, an efficient transfer of MeSeCys resulting in comparable concentrations in both compartments was observed, indicating that MeSeCys was shuttled through the cells and did not contribute to their Se pool.

The yet uncharacterized Se species selenoneine showed a crossover behaviour similar to that of selenite. However, it is unlikely to cross the intestinal barrier via the paracellular route, as its simultaneous incubation in both chambers led to an accumulation in the basolateral compartment, pointing out a transcellular pathway. Moreover, the cellular Se contents 
indicated a high cellular bioavailability of selenoneine, demonstrating that it is efficiently taken up by Caco-2 cells. It has been proposed that due to selenoneine's structural similarity with ergothioneine, it may be taken up via the same transporter, the organic cation/carnitine transporter 1 (OCTN-1, SLC22A4). ${ }^{[7,37]}$ OCTN-1 expression has been confirmed in Caco-2

5 cells $^{[38,39]}$ and various other cultured cells and human tissues, ${ }^{[40]}$ suggesting that selenoneine could be taken up by other cell types as well. However, whether selenoneine is indeed transported via OCTN-1 or via another transporter requires further investigation. Besides persuing the elucidation of selenoneine's path into the body, it might also be of future interest to investigate its dependence on the presence of its sulfur analogue ergothioneine, since the presence of analogous sulfur species has previously been found to reduce the transport of selenomethionine and MeSeCys in the intestinal barrier model. ${ }^{[22]}$

As the human metabolism of selenoneine is widely unknown, we carried out HPLC-MS based speciation studies in culture dishes as well as during the transfer experiments to investigate whether Caco-2 cells can metabolize selenoneine. When selenoneine was applied to the cells, it was the major Se species in the media and cell lysates throughout all experiments. Results obtained in the Transwell system indicated that selenoneine is taken up by the cells and transported across the intestinal barrier mainly unmetabolized. However, the formation of Semethylselenoneine as shown by the time dependent sampling and investigation of culture media in the culture dish experiments confirms at least a partial metabolism. This metabolism might be even more pronounced if selenoneine was present in its reduced monomeric form, as reduction has to precede methylation when the oxidized species is present. The fact that methylation preferentially occurs when selenoneine is applied on the luminal side of the intestinal barrier model has wider implications. Selenoneine present in food is expected to exhibit a similar fate, particularly if it is already partially present in its reduced form. Whether 25 Se-methylselenoneine is only an excretory metabolite of selenoneine as previously assumed, ${ }^{[11]}$ or also has other biological functions is one of the questions that remain to be elucidated in future studies in order to fully understand its role in human health. 


\section{$\underline{5 \text { Concluding remarks }}$}

The results of the present study demonstrate that selenoneine passes the intestinal barrier and is highly bioavailable to Caco-2 cells. First mechanistic insights point towards a transcellular, carrier-mediated transport that is directed towards the blood-facing compartment.

5 Furthermore, the identification of Se-methylselenoneine in culture medium and cell lysates following selenoneine incubation demonstrates a partial presystemic metabolism of selenoneine by Caco-2 cells. However, the unmetabolized species was the predominant form in all medium and cell samples. Therefore, further efforts should address its transport via blood circulation, its bioavailability in potential target organs, as well as main sites and routes of its metabolism, to form the basis for a profound characterization of this purportedly health-relevant Se species.

\section{Acknowledgments}

This work was funded by the German Research Foundation (DFG), grant number SCHW 903/9-1, and the Austrian Science Fund (FWF), project number I 2262-N28, as well as the DFG Research Unit TraceAge (FOR 2558). We thank Kevin A. Francesconi for valuable scientific discussions.

\section{Author contributions}

I.R. and N.K. contributed equally to this study. I.R. performed the cell culture experiments, investigated cytotoxicity and the transfer of Se species across the intestinal barrier. N.K. and D.K. performed Se speciation analysis. I.R. and N.K. drafted and wrote the manuscript. J.B., D.K. and T.S. supervised the experiments, contributed to data interpretation and revised the manuscript critically. All authors have approved the final version of the manuscript. 


\section{Declarations of interest}

The authors declare no conflict of interest.

\section{References}

(1) M. P. Rayman, Lancet 2012, 379, 1256.

(2) U.S. Department for Health and Human Services, 2003.

(3) E. Jablonska, M. Vinceti, J. Environ. Sci. Heal. - Part C Environ. Carcinog. Ecotoxicol. Rev. 2015, 33, 328.

(4) C. M. Weekley, H. H. Harris, Chem. Soc. Rev. 2013, 42, 8870.

(5) Y. Yamashita, M. Yamashita, J. Biol. Chem. 2010, 285, 18134.

(6) I. K. Cheah, B. Halliwell, Biochim. Biophys. Acta 2012, 1822, 784.

(7) M. Yamashita, Y. Yamashita, T. Suzuki, Y. Kani, N. Mizusawa, S. Imamura, K. Takemoto, T. Hara, M. A. Hossain, T. Yabu, K. Touhata, Mar. Biotechnol. 2013, 15, 559.

(8) Z. Pedrero Zayas, L. Ouerdane, S. Mounicou, R. Lobinski, M. Monperrus, D. Amouroux, Anal. Bioanal. Chem. 2014, 406, 1121.

(9) Y. Yamashita, H. Amlund, T. Suzuki, T. Hara, M. A. Hossain, T. Yabu, K. Touhata, M. Yamashita, Fish. Sci. 2011, 77, 679.

(10) M. Yamashita, Y. Yamashita, T. Ando, J. Wakamiya, S. Akiba, Biol. Trace Elem. Res. 2013, 156, 36.

(11) M. Klein, L. Ouerdane, M. Bueno, F. Pannier, Metallomics 2011, 3, 513.

(12) N. Kroepfl, K. A. Francesconi, T. Schwerdtle, D. Kuehnelt, J. Anal. At. Spectrom. 2019, 34, 127.

(13) N. G. Turrini, N. Kroepfl, K. B. Jensen, T. C. Reiter, K. A. Francesconi, T. Schwerdtle, W. Kroutil, D. Kuehnelt, Metallomics 2018, 10, 1532.

(14) N. Kroepfl, K. B. Jensen, K. A. Francesconi, D. Kuehnelt, Anal. Bioanal. Chem. 2015, 407, 7713. 
(15) L. Leffers, C. A. Wehe, S. Hüwel, M. Bartel, F. Ebert, M. S. Taleshi, H.-J. Galla, U. Karst, K. A. Francesconi, T. Schwerdtle, Metallomics 2013, 5, 1031.

(16) P. Artursson, J. Karlsson, Biochem. Biophys. Res. Commun. 1991, 175, 880.

(17) Y. Sambuy, I. DeAngelis, G. Ranaldi, M. L. Scarino, A. Stammati, F. Zucco, Cell Biol. Toxicol. 2005, 21, 1.

(18) D. A. Volpe, J. Pharm. Sci. 2008, 97, 712.

(19) G. Leblondel, Y. Mauras, A. Cailleux, P. Allain, Biol. Trace Elem. Res. 2001, 83, 191.

(20) H. Zeng, M. I. Jackson, W.-H. Cheng, G. F. Combs Jr, Biol. Trace Elem. Res. 2011, 143, 1209.

(21) B. Gammelgaard, L. H. Rasmussen, C. Gabel-Jensen, B. Steffansen, Biol. Trace Elem. Res. 2012, 145, 248.

(22) C. Thiry, A. Ruttens, L. Pussemier, Y.-J. Schneider, Br. J. Nutr. 2013, 109, 2126.

(23) K. Takahashi, N. Suzuki, Y. Ogra, Int. J. Mol. Sci. 2017, 18, e506.

(24) T. A. Marschall, N. Kroepfl, K. B. Jensen, J. Bornhorst, B. Meermann, D. Kuehnelt, T. Schwerdtle, Metallomics 2017, 9, 268.

(25) M. M. Bradford, Anal. Biochem. 1976, 72, 248.

(26) B. Gammelgaard, O. Jøns, J. Anal. At. Spectrom. 1999, 14, 867.

(27) S. Kokarnig, D. Kuehnelt, M. Stiboller, U. Hartleb, K. A. Francesconi, Anal. Bioanal. Chem. 2011, 400, 2323.

(28) L. Zhang, Y. Zheng, M. S. S. Chow, Z. Zuo, Int. J. Pharm. 2004, 287, 1.

(29) Y. Yamashita, World J. Biol. Chem. 2010, 1, 144.

(30) T. A. Marschall, J. Bornhorst, D. Kuehnelt, T. Schwerdtle, Mol. Nutr. Food Res. 2016, 60, 2622.

(31) K. Lunøe, C. Gabel-Jensen, S. Stürup, L. Andresen, S. Skov, B. Gammelgaard, Metallomics 2011, 3, 162. 
(32) L. L. Flores Villavicencio, G. Cruz-Jiménez, G. Barbosa-Sabanero, C. KornhauserAraujo, M. E. Mendoza-Garrido, G. de La Rosa, M. Sabanero-López, Bioinorg. Chem. Appl. 2014, 2014, 923834.

(33) E. M. Ammar, D. Couri, Neurotoxicology 1981, 2, 383.

(34) S. C. Vendeland, J. T. Deagen, J. A. Butler, P. D. Whanger, Biometals 1994, 7, 305.

(35) A. Nickel, G. Kottra, G. Schmidt, J. Danier, T. Hofmann, H. Daniel, Chem. Biol. Interact. 2009, 177, 234.

(36) R. Hayeshi, C. Hilgendorf, P. Artursson, P. Augustijns, B. Brodin, P. Dehertogh, K. Fisher, L. Fossati, E. Hovenkamp, T. Korjamo, C. Masungi, N. Maubon, R. Mols, A. Müllertz, J. Mönkkönen, C. O’Driscoll, H.M. Oppers-Tiemissen, E. G. E. Ragnarsson, M. Rooseboom, A.-L. Ungell, Eur. J. Pharm. Sci. 2008, 35, 383.

(37) D. Gründemann, S. Harlfinger, S. Golz, A. Geerts, A. Lazar, R. Berkels, N. Jung, A. Rubbert, E. Schömig, Proc. Natl. Acad. Sci. 2005, 102, 5256.

(38) A. M. Lamhonwah, C. Ackerley, R. Onizuka, A. Tilups, D. Lamhonwah, C. Chung, K. S. Tao, R. Tellier, I. Tein, Biochem. Biophys. Res. Commun. 2005, 337, 1165.

(39) N. Maubon, M. Le Vee, L. Fossati, M. Audry, E. Le Ferrec, S. Bolze, O. Fardel, Fundam. Clin. Pharmacol. 2007, 21, 659.

(40) L. Pochini, M. Scalise, M. Galluccio, C. Indiveri, J. Biomol. Screen. 2013, 18, 851. 


\section{Figure legends}

Figure 1. Chemical structures of the investigated Se species. Selenoneine exists in a reduced, monomeric form and an oxidized, dimeric form. Selenite and MeSeCys were used as reference species.

Figure 2. Cell viability assessed by lysosomal integrity (A) and dehydrogenase activity (B) after $72 \mathrm{~h}$ of incubation with Se species in differentiated Caco-2 cells. Shown are mean values of at least two individual passages with three independent determinations each $+S D,{ }^{*} p<$ $0.05,{ }^{* *} p<0.001$ vs. untreated control cells. Selenite - , MeSeCys - , selenoneine - .

Figure 3. Effects of Se species on the Caco-2 barrier determined by measurement of the TEER (A, C, E) and electrical capacitance (B, D, F) after apical incubation with selenite (A and B), MeSeCys (C and $\mathbf{D})$ and selenoneine (E and $\mathbf{F})$. Shown are mean values of at least two individual passages with two independent determinations each, normalized to the initial value.

Figure 4. Se transfer across the intestinal Caco-2 barrier model after incubation with $1 \mu \mathrm{M}$ selenite (A), $1 \mu \mathrm{M}$ MeSeCys (B) or $0.5 \mu \mathrm{M}$ selenoneine (C) in the apical compartment. Shown are mean values of at least two individual passages with two independent determinations each + SD.

Figure 5. Se transfer across the intestinal Caco-2 barrier model after simultaneous incubation with $1 \mu \mathrm{M}$ selenite $(\mathbf{A}), 1 \mu \mathrm{M}$ MeSeCys $(\mathbf{B})$ or $0.5 \mu \mathrm{M}$ selenoneine $(\mathbf{C})$ in the apical and basolateral compartment. Shown are mean values of at least two individual passages with two independent determinations each + SD. 
Figure 6. RP-HPLC/ICPMS elution profile of a lysate of Caco-2 cells incubated with $1 \mu \mathrm{M}$ selenoneine in a culture dish for $72 \mathrm{~h}$ not treated by filtration (red line) or treated with MWCO (3000 Da) filtration (blue line); column: Atlantis dC18 $(4.6 \times 150 \mathrm{~mm})$, mobile phase: $20 \mathrm{mM}$ ammonium formate, $3 \%$ methanol, $\mathrm{pH} 3.0$, flow rate: $1.0 \mathrm{~mL} \mathrm{~min}{ }^{-1}$, injection volume: $10 \mu \mathrm{L}$.

Figure 7. HPLC/Orbitrap MS of a Caco-2 cell lysate from a culture dish treated with $1 \mu \mathrm{M}$ selenoneine for $72 \mathrm{~h}$. (A) calculated isotope pattern for Se-methylselenoneine, (B) spectrum of Se-methylselenoneine, (C) fragmentation of $\mathrm{m} / \mathrm{z}$ 292.056; Chromatographic conditions: Column: Atlantis dC18, $4.6 \times 150 \mathrm{~mm}$, column temperature: $30{ }^{\circ} \mathrm{C}$, mobile phase: $20 \mathrm{mM}$ ammonium formate, $3 \%$ methanol, $\mathrm{pH} 3.0$, flow rate: $1.0 \mathrm{~mL} \mathrm{~min}^{-1}$, injection volume: $10 \mu \mathrm{L}$. 
Table 1. The effective concentrations reducing cell viability by $30 \%\left(\mathrm{EC}_{30}\right)$ after $72 \mathrm{~h}$ of incubation with the Se species in differentiated Caco-2 cells. The values were determined by measuring lysosomal integrity (neutral red assay) and dehydrogenase activity (CCK-8 assay)

\begin{tabular}{|c|c|c|}
\hline \multirow[b]{2}{*}{ Se species } & \multicolumn{2}{|c|}{$\mathrm{EC}_{30}[\mu \mathrm{M}]$} \\
\hline & Lysosomal integrity & Dehydrogenase activity \\
\hline selenite & 13 & 12 \\
\hline MeSeCys & 176 & $>500$ \\
\hline selenoneine & $>100$ & $>100$ \\
\hline
\end{tabular}


Table 2. Cellular Se contents of differentiated Caco-2 cells after $72 \mathrm{~h}$ of incubation with the Se species in the apical compartment. Shown are mean values of at least two individual passages with two independent determinations each $\pm S D,{ }^{*} p<0.05,{ }^{* * *} p<0.001$ vs. control.

\begin{tabular}{l|l|l} 
Incubation & ng Se/mg protein & \% of applied Se \\
\hline control & $1.2 \pm 0.1$ & $1.6 \pm 0.4$ \\
$1 \mu \mathrm{M}$ selenite & $3.0 \pm 0.9^{*}$ & $0.8 \pm 0.1$ \\
$1 \mu \mathrm{M}$ MeSeCys & $1.4 \pm 0.1$ & $7.6 \pm 1.0$ \\
$0.5 \mu \mathrm{M}$ selenoneine & $5.3 \pm 0.2^{* * *}$ &
\end{tabular}


Table 3. Selenoneine and total Se concentrations in cell lysates, apical, and basolateral medium from Caco-2 intestinal barrier model experiments after incubation with $0.5 \mu \mathrm{M}-10 \mu \mathrm{M}$ selenoneine for $72 \mathrm{~h}$; Se speciation analysis performed by HPLC/ICPMS using chromatographic condition I (Supplementary Table 1).

\begin{tabular}{|c|c|c|c|c|c|c|c|c|c|}
\hline \multirow{2}{*}{$\begin{array}{l}\text { Selenoneine concentration } \\
\text { used for incubation / } \\
\text { compartment of } \\
\text { application }\end{array}$} & \multicolumn{3}{|c|}{ Medium apical } & \multicolumn{3}{|c|}{ Medium basolateral } & \multicolumn{3}{|c|}{ Lysate } \\
\hline & $\begin{array}{l}\text { Selenoneine } \\
\text { [ } \mu \mathrm{g} \mathrm{Se} L^{-1} \text { ] }\end{array}$ & $\begin{array}{c}\text { Total Se } \\
\text { [ } \mu \mathrm{g} \mathrm{Se} \mathrm{L}^{-1} \text { ] }\end{array}$ & $\begin{array}{c}\% \text { of } \\
\text { total Se }\end{array}$ & $\begin{array}{c}\text { Selenoneine } \\
{\left[\mu \mathrm{g} \mathrm{Se} L^{-1}\right]}\end{array}$ & $\begin{array}{c}\text { Total Se } \\
{\left[\mu \mathrm{g} \mathrm{Se} \mathrm{L}^{-1} \text { ] }\right.}\end{array}$ & $\begin{array}{c}\% \text { of } \\
\text { total Se }\end{array}$ & $\begin{array}{c}\text { Selenoneine } \\
\text { [ng Se per } \\
\text { pellet] }\end{array}$ & $\begin{array}{c}\text { Total Se } \\
\text { [ng Se per pellet] }\end{array}$ & $\begin{array}{c}\% \text { of } \\
\text { total Se }\end{array}$ \\
\hline $0.5 \mu \mathrm{M} /$ apical & 35,34 & 35,32 & 100,104 & $10,9.0$ & $11,8.9$ & 93,101 & $1.3,0.9$ & $1.7,1.4$ & 78,64 \\
\hline $1 \mu \mathrm{M} /$ apical $^{\mathrm{a}}$ & $63 \pm 14$ & $71 \pm 23$ & $92 \pm 18$ & $25 \pm 5$ & $26 \pm 9$ & $103 \pm 23$ & $2.4 \pm 1.5$ & $4.2 \pm 0.4$ & $55 \pm 32$ \\
\hline $10 \mu \mathrm{M} /$ apical $^{\mathrm{a}}$ & $916 \pm 82$ & $1070 \pm 140$ & $86 \pm 5$ & $136 \pm 10$ & $137 \pm 16$ & $100 \pm 10$ & $24 \pm 3$ & $26 \pm 2$ & $91 \pm 11$ \\
\hline $0.5 \mu \mathrm{M} /$ both sides & 37,37 & 38,34 & 96,108 & 78,84 & 72,80 & 109,104 & $1.3,1.4$ & $1.7,2.2$ & 76,66 \\
\hline $1 \mu \mathrm{M} /$ both sides $^{b}$ & $86 \pm 3$ & $87 \pm 5$ & $99 \pm 8$ & $171 \pm 11$ & $159 \pm 22$ & $108 \pm 8$ & $3.2 \pm 0.2$ & $4.0 \pm 0.3$ & $81 \pm 6$ \\
\hline $1 \mu \mathrm{M}$ / basolateral & $4.6,4.4$ & $5.8,6.1$ & 79,72 & 154,152 & 136,135 & 113,113 & $0.3,0.2$ & $0.4,0.3$ & 64,68 \\
\hline
\end{tabular}

${ }^{a}$ Mean $\pm S D, n=4$ experiments

${ }^{\mathrm{b}}$ Mean $\pm S D, \mathrm{n}=3$ experiments 


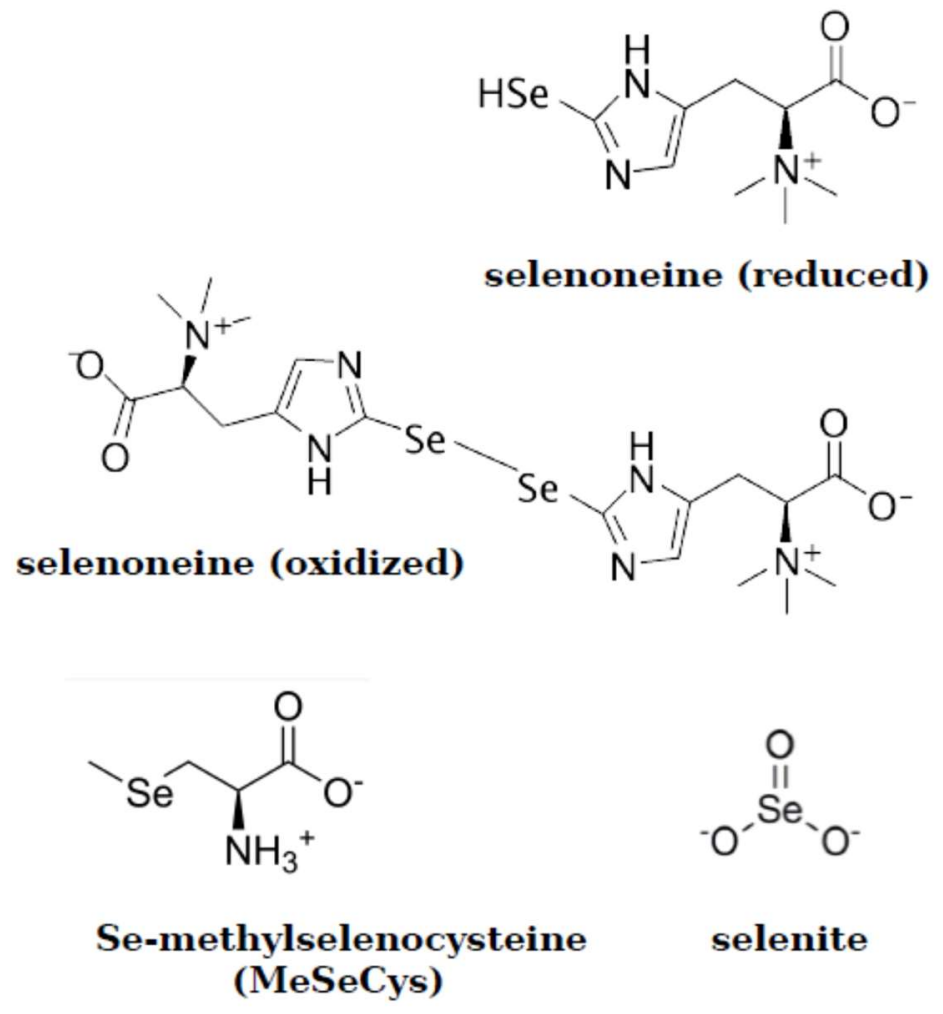

Figure 1. Chemical structures of the investigated Se species. Selenoneine exists in a reduced, monomeric form and an oxidized, dimeric form. Selenite and MeSeCys were used as reference species. 

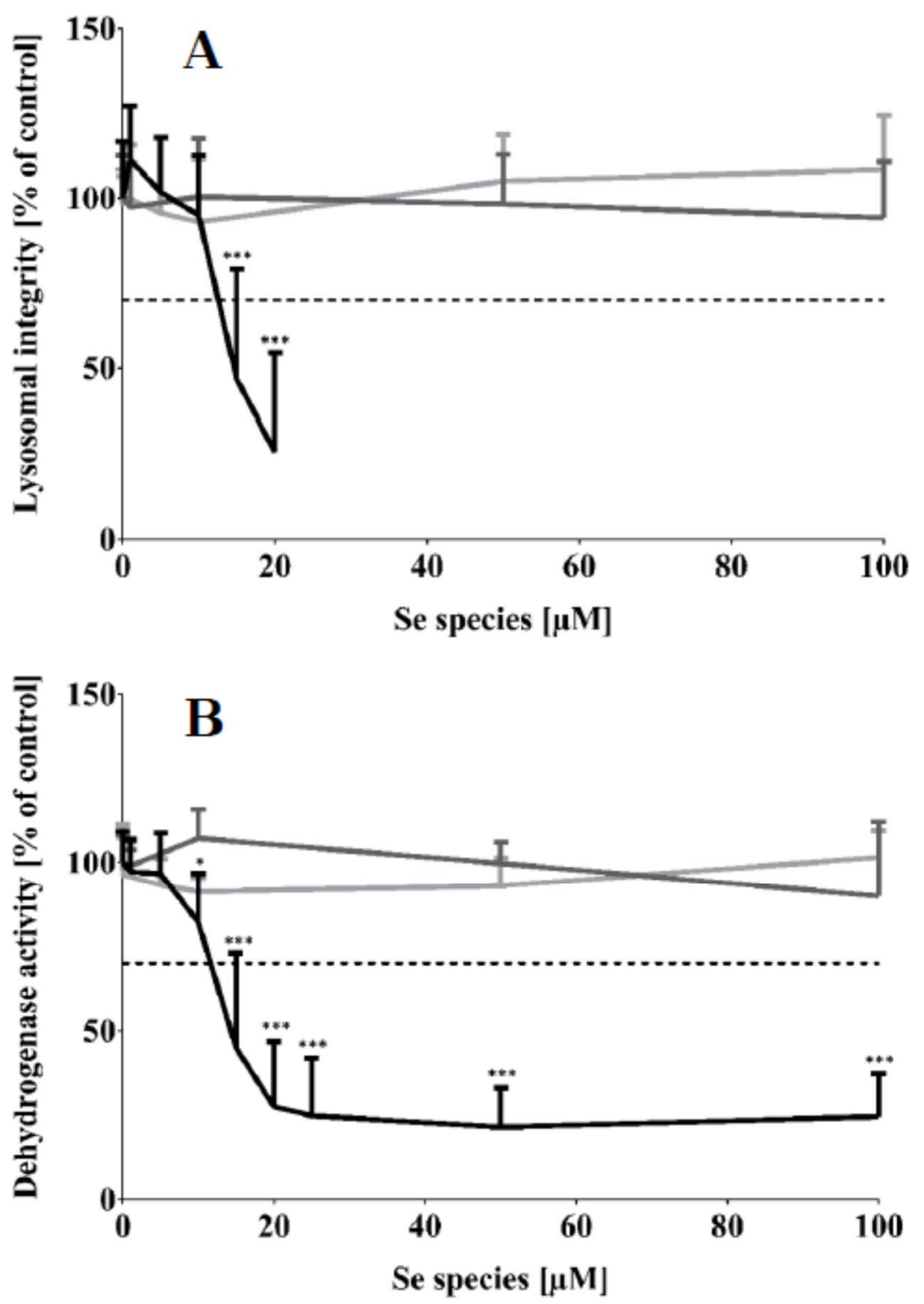

Figure 2. Cell viability assessed by lysosomal integrity (A) and dehydrogenase activity (B) after $72 \mathrm{~h}$ of incubation with Se species in differentiated Caco-2 cells. Shown are mean values of at least two individual passages with three independent determinations each $+\mathrm{SD},{ }^{*} \mathrm{p}<$ $5 \quad 0.05,{ }^{* * *} p<0.001$ vs. untreated control cells. Selenite - , MeSeCys - , selenoneine - . 

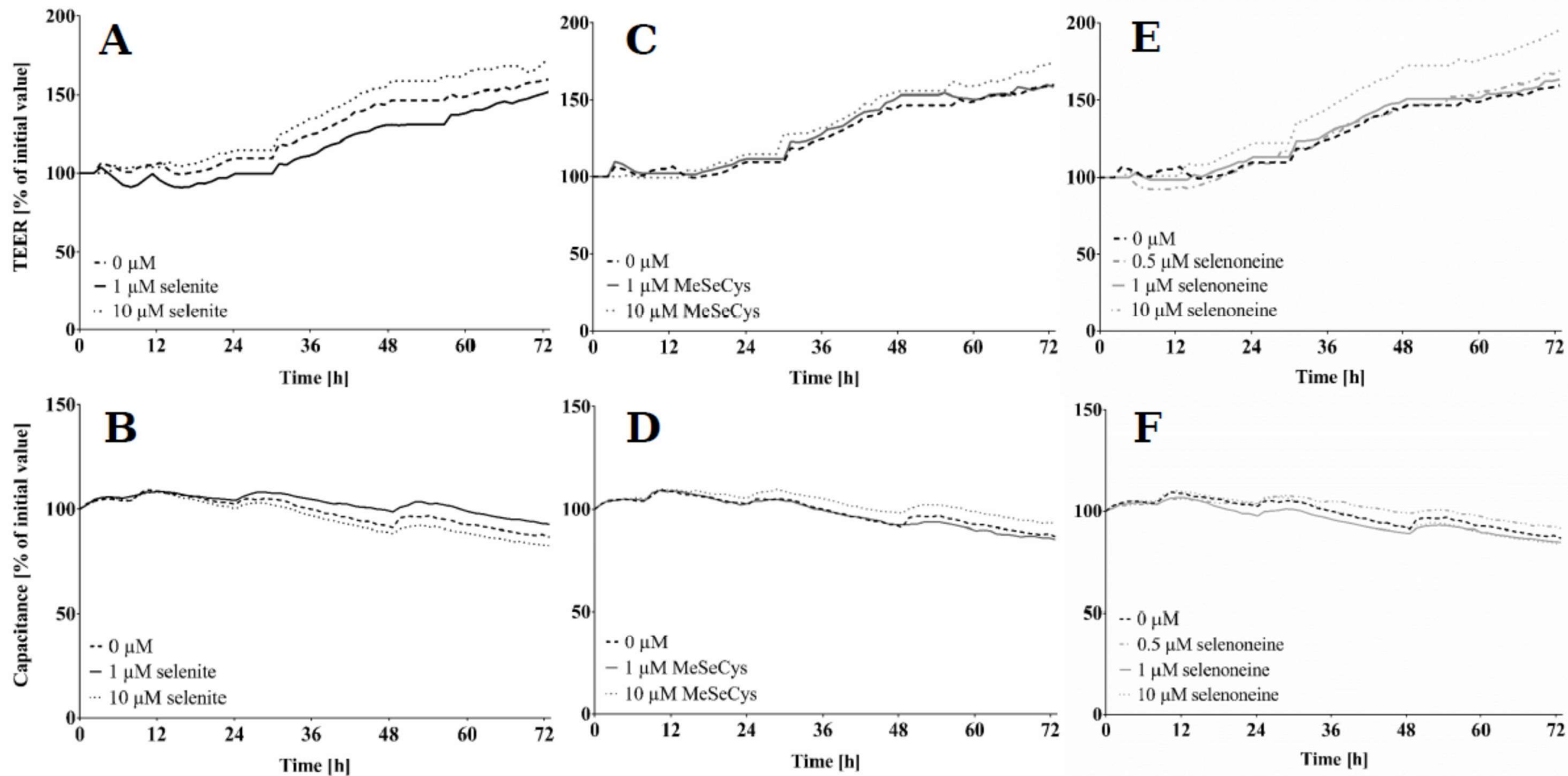

Figure 3. Effects of Se species on the Caco-2 barrier determined by measurement of the TEER (A, C, E) and electrical capacitance (B, D, F) after apical incubation with selenite (A and B), MeSeCys ( $\mathbf{C}$ and $\mathbf{D})$ and selenoneine (E and $\mathbf{F})$. Shown are mean values of at least two individual passages with two independent determinations each, normalized to the initial value. 

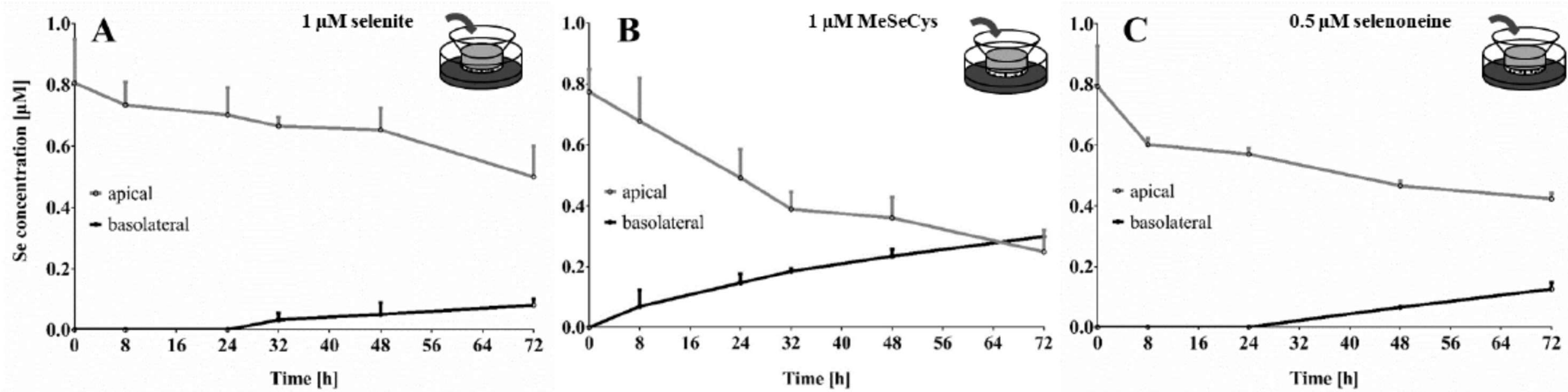

Figure 4. Se transfer across the intestinal Caco-2 barrier model after incubation with $1 \mu \mathrm{M}$ selenite $(\mathbf{A}), 1 \mu \mathrm{M}$ MeSeCys $(\mathbf{B})$ or $0.5 \mu \mathrm{M}$ selenoneine (C) in the apical compartment. Shown are mean values of at least two individual passages with two independent determinations each + SD. 

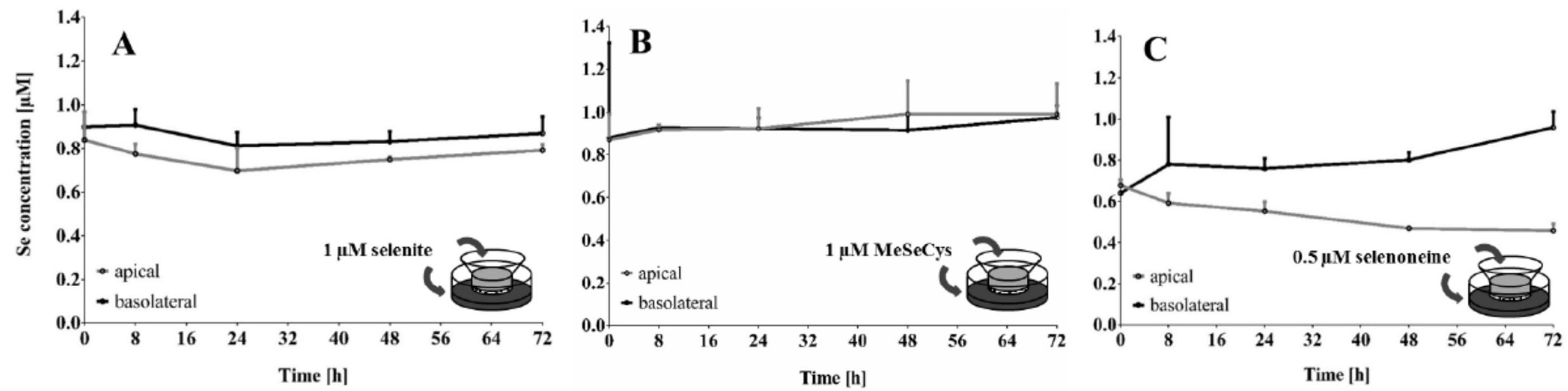

Figure 5. Se transfer across the intestinal Caco-2 barrier model after simultaneous incubation with $1 \mu \mathrm{M}$ selenite $(\mathbf{A}), 1 \mu \mathrm{M}$ MeSeCys $(\mathbf{B})$ or $0.5 \mu \mathrm{M}$ selenoneine (C) in the apical and basolateral compartment. Shown are mean values of at least two individual passages with two independent determinations each + SD. 


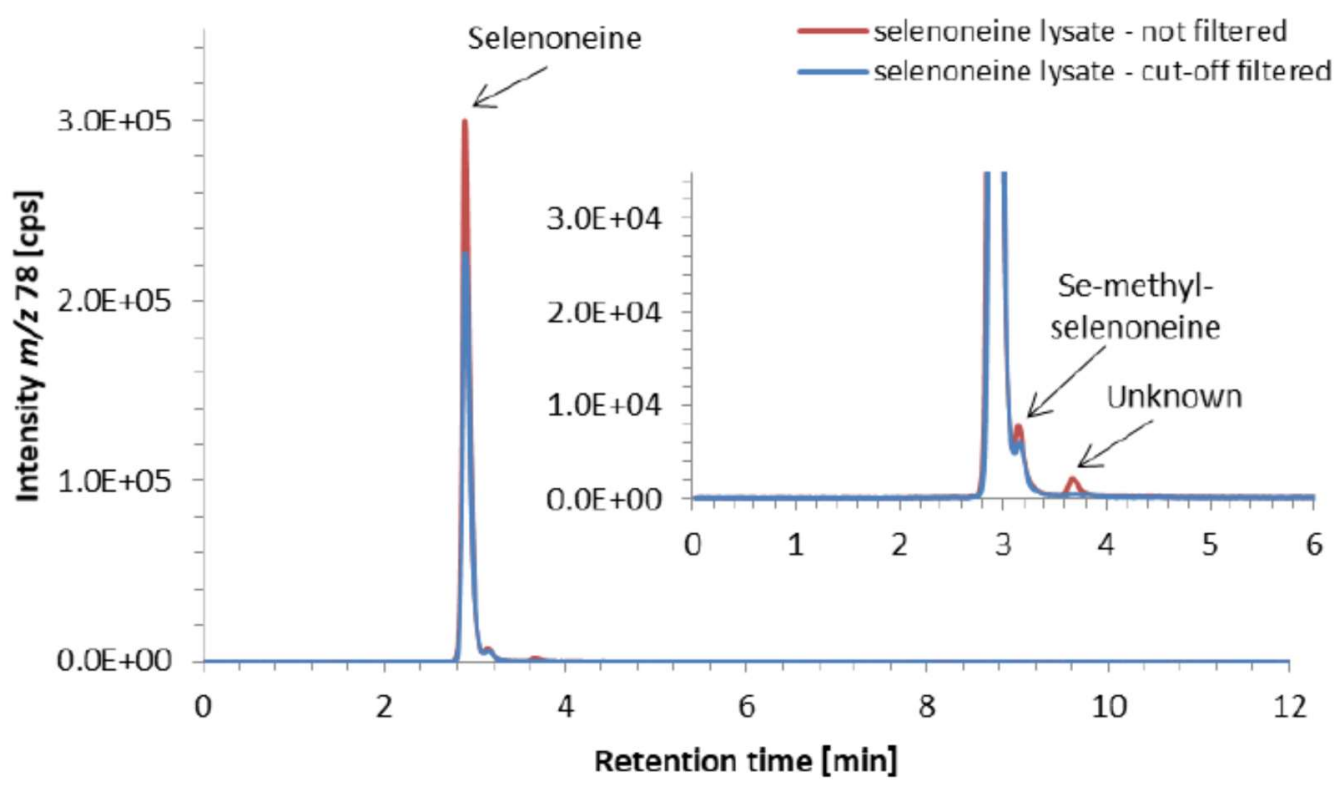

Figure 6. RP-HPLC/ICPMS elution profile of a lysate of Caco-2 cells incubated with $1 \mu \mathrm{M}$ selenoneine in a culture dish for $72 \mathrm{~h}$ not treated by filtration (red line) or treated with MWCO

5 (3000 Da) filtration (blue line); column: Atlantis dC18 $(4.6 \times 150 \mathrm{~mm})$, mobile phase: $20 \mathrm{mM}$ ammonium formate, $3 \%$ methanol, $\mathrm{pH} 3.0$, flow rate: $1.0 \mathrm{~mL} \mathrm{~min}^{-1}$, injection volume: $10 \mu \mathrm{L}$. 

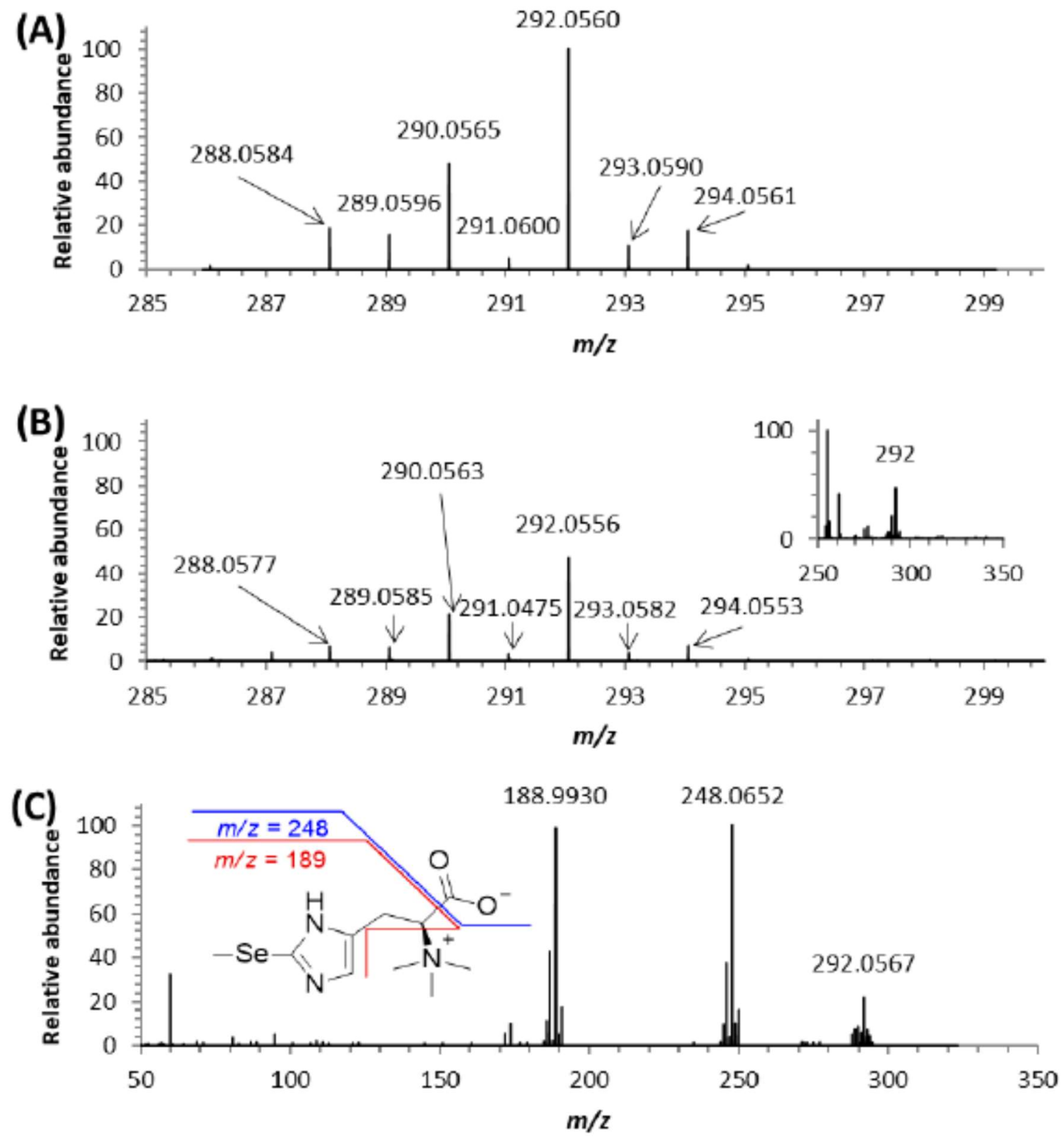

Figure 7. HPLC/Orbitrap MS of a Caco-2 cell lysate from a culture dish treated with $1 \mu \mathrm{M}$ selenoneine for 72 h. (A) calculated isotope pattern for Se-methylselenoneine, (B) spectrum of Se-methylselenoneine, (C) fragmentation of $\mathrm{m} / \mathrm{z}$ 292.056; Chromatographic conditions:

5 Column: Atlantis dC18, $4.6 \times 150 \mathrm{~mm}$, column temperature: $30{ }^{\circ} \mathrm{C}$, mobile phase: $20 \mathrm{mM}$ ammonium formate, $3 \%$ methanol, $\mathrm{pH} 3.0$, flow rate: $1.0 \mathrm{~mL} \mathrm{~min}^{-1}$, injection volume: $10 \mu \mathrm{L}$. 
Supporting Information 
Supplementary Table 1. Chromatographic conditions for the quantitative determination of Se species in Caco-2 cell lysates and cell culture media.

\begin{tabular}{lccccc}
\hline & $\begin{array}{c}\text { Separation } \\
\text { mechanism }\end{array}$ & Column & $\begin{array}{c}\text { Column } \\
\text { temperature }\end{array}$ & Mobile phase & Flow rate \\
\hline I & Reversed-phase & Waters Atlantis ${ }^{\circ} \mathrm{dC} 18$ & $30^{\circ} \mathrm{C}$ & $20 \mathrm{mM}$ ammonium formate, & $1.0 \mathrm{~mL} \mathrm{~min}^{-1}$ \\
& & & $3 \% \mathrm{MeOH}, \mathrm{pH} 3.0^{\mathrm{a}}$ & \\
II & Anion-exchange & Dionex lonPac ${ }^{\mathrm{TM}} \mathrm{AS} 14-$ & $40^{\circ} \mathrm{C}$ & $5 \mathrm{mM}$ malonate, $\mathrm{pH} 9.5^{\mathrm{b}}$ & $0.7 \mathrm{~mL} \mathrm{~min}^{-1}$ \\
& $\mathrm{~A}(3 \times 150 \mathrm{~mm})$ & & & \\
\hline
\end{tabular}

$10 \quad{ }^{a} \mathrm{pH}$ adjusted with formic acid

${ }^{\mathrm{b}} \mathrm{pH}$ adjusted with ammonia solution 
Supplementary Table 2. Cellular Se contents of differentiated Caco-2 cells after $72 \mathrm{~h}$ of incubation with the Se species in the apical compartment. Shown are mean values of at least two individual passages with two independent determinations each $\pm S D, * * p<0.01, * * * p 0.001$ vs. control.
Incubation
ng Se/mg protein
$\%$ of applied Se

control

$1.2 \pm 0.1$

$11.9 \pm 3.8^{* *}$

$0.7 \pm 0.2$

$10 \mu \mathrm{M}$ selenite

\section{$5.5 \pm 1.7$}

$102 \pm 13^{* * *}$

$10 \mu \mathrm{M}$ selenoneine

$18.0 \pm 2.9^{* * *}$

$0.4 \pm 0.1$

$6.6 \pm 0.3$

$1 \mu \mathrm{M}$ selenoneine

$10.7 \pm 1.0$ 
Supplementary Table 3. Selenoneine and total Se concentrations in cell culture medium and cell lysates of Caco-2 culture dish experiments after incubation with $0.5 \mu \mathrm{M}$ or $1 \mu \mathrm{M}$ selenoneine for $5 \mathrm{~min}, 8 \mathrm{~h}$, or $72 \mathrm{~h}$; Se speciation analysis performed by HPLC/ICPMS using chromatographic condition I (Supplementary Table 1).

\begin{tabular}{|c|c|c|c|c|}
\hline \multirow[t]{2}{*}{ Analyte } & \multicolumn{2}{|c|}{$0.5 \mu \mathrm{M}$ selenoneine incubated } & \multicolumn{2}{|c|}{$1 \mu \mathrm{M}$ selenoneine incubated } \\
\hline & Selenoneine & Total Se & Selenoneine & Total Se \\
\hline Culture medium, 5 min incubation $\left[\mu \mathrm{g} \mathrm{Se}^{-1}\right]$ & 66 & 73 & 144 & 151 \\
\hline Culture medium, $8 \mathrm{~h}$ incubation [ $\mu \mathrm{g} \mathrm{Se} \mathrm{L}^{-1}$ ] & 62 & 65 & 135 & 163 \\
\hline Culture medium, 72 min incubation [ $\mu \mathrm{g} \mathrm{Se} \mathrm{L}^{-1}$ ] & 51 & $57 \pm 1^{*}$ & 115 & $128 \pm 1^{\mathrm{a}}$ \\
\hline Cell lysate [ng Se per cell pellet] & 21 & 24 & 44 & 47 \\
\hline
\end{tabular}

${ }^{a}$ Mean $\pm S D, n=3$ digests 

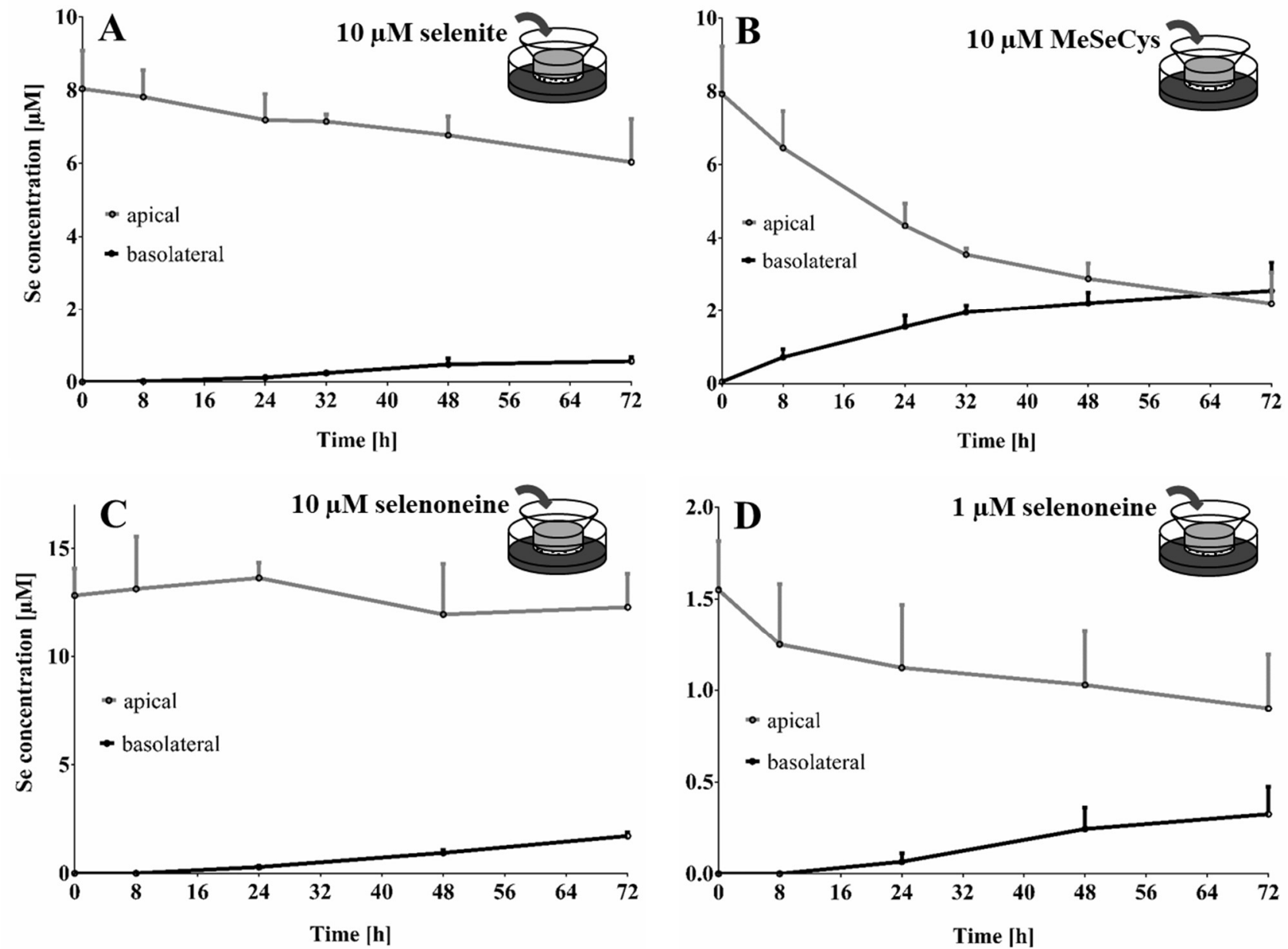

Supplementary Figure S1. Se transfer across the intestinal Caco-2 barrier model after incubation with $10 \mu \mathrm{M}$ selenite (A), $10 \mu \mathrm{M}$ MeSeCys (B), $10 \mu \mathrm{M}$ selenoneine (C) or (D) $1 \mu \mathrm{M}$ selenoneine in the apical compartment. Shown are mean values of at least two individual passages with two independent determinations each + SD. 


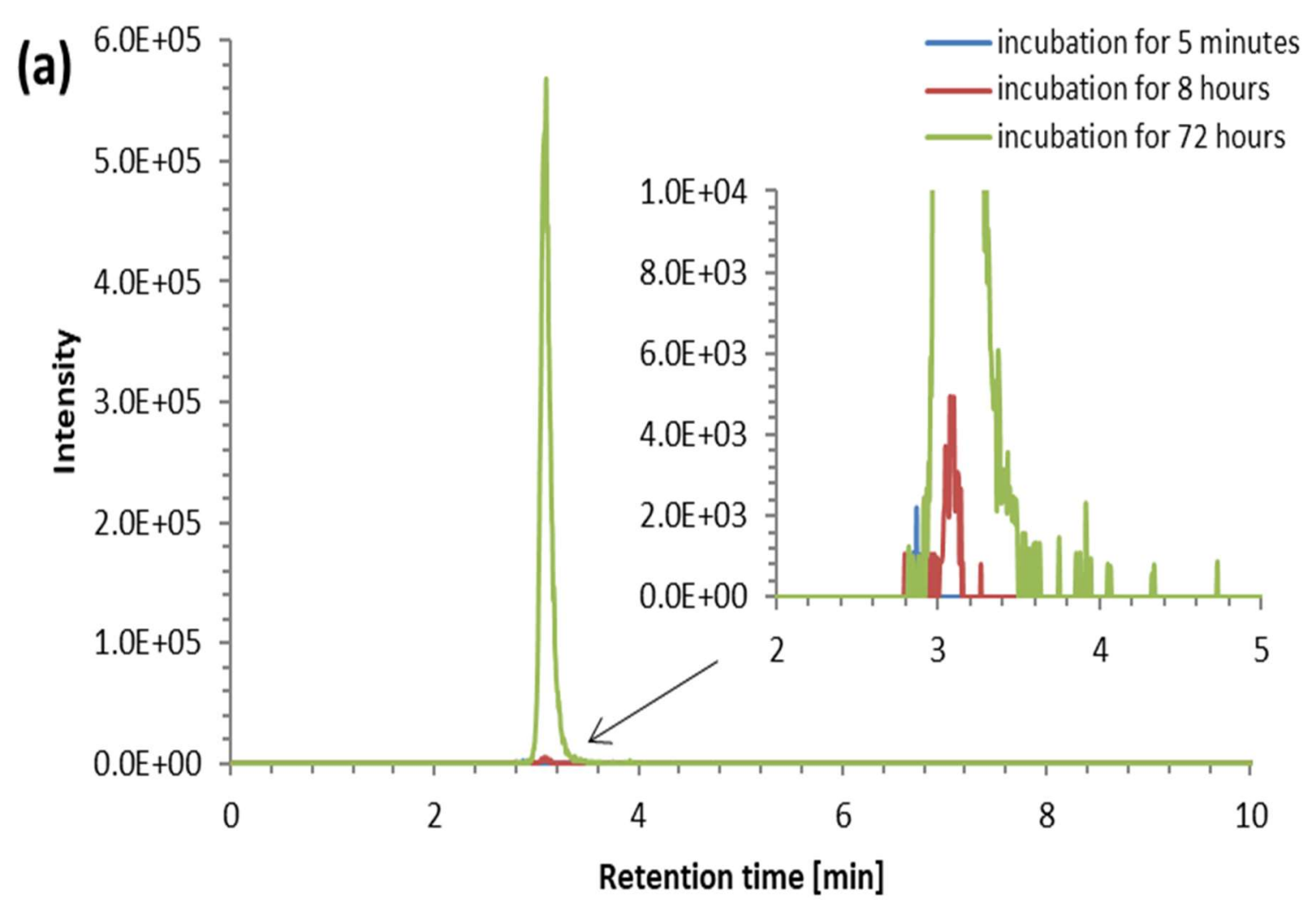

Supplementary Figure S2. HPLC/Orbitrap MS of Caco-2 cell culture media from a cell culture dish treated with $1 \mu \mathrm{M}$ selenoneine. (A) chromatograms $(\mathrm{m} / \mathrm{z}$ $292.0556 \pm 2 \mathrm{mmu}$ ) after treatment with selenoneine for $5 \mathrm{~min}$ (blue line), $8 \mathrm{~h}$ (red line) and $72 \mathrm{~h}$ (green line); Chromatographic conditions: Column: Atlantis $\mathrm{dC} 18,4.6 \times 150 \mathrm{~mm}$, column temperature: $30^{\circ} \mathrm{C}$, mobile phase: $20 \mathrm{mM}$ ammonium formate, $3 \%$ methanol, $\mathrm{pH} 3.0$, flow rate: $1.0 \mathrm{~mL} \mathrm{~min}{ }^{-1}$, injection volume: 

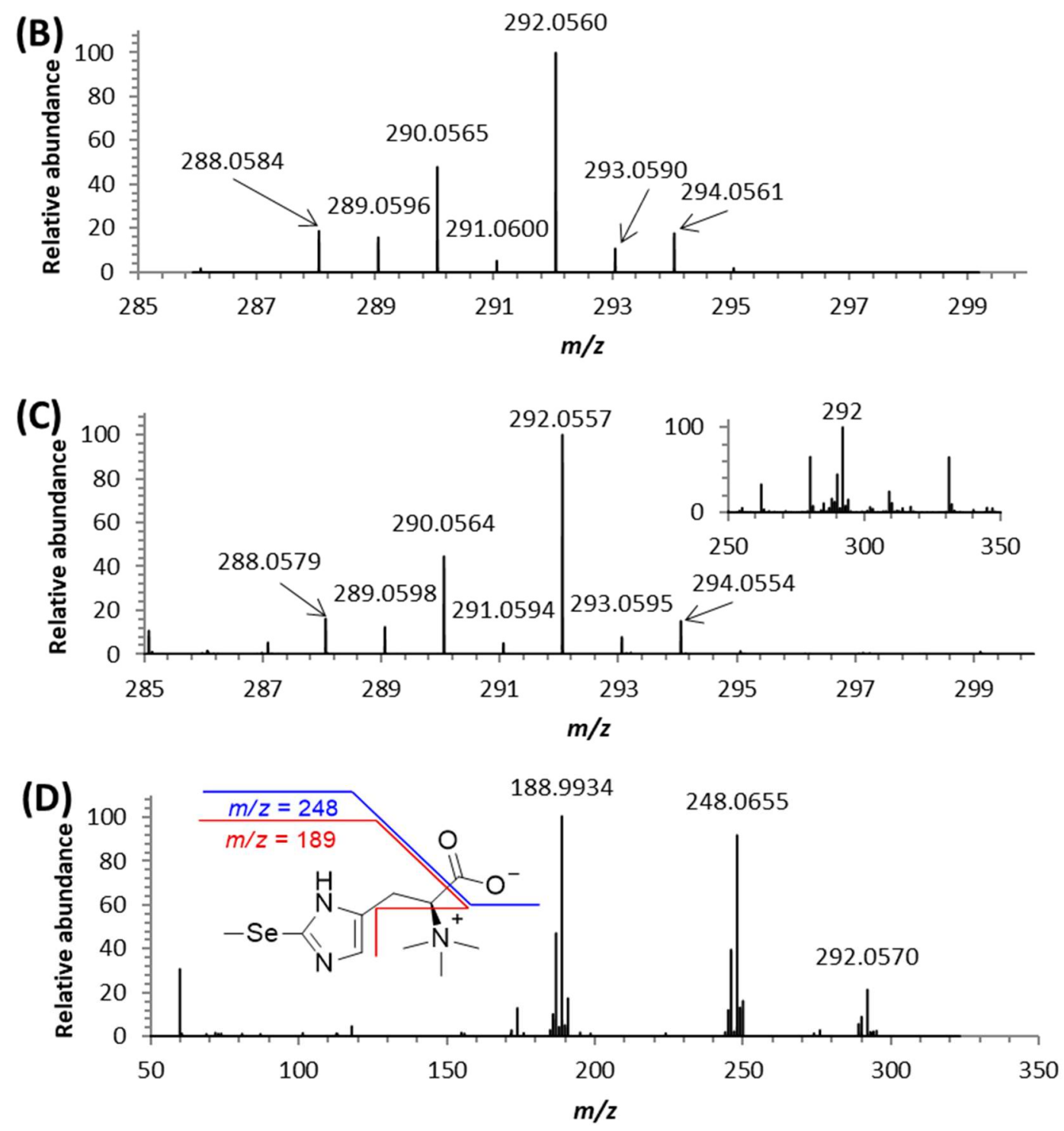

Supplementary Figure S2 continued. HPLC/Orbitrap MS of Caco-2 cell culture media from a cell culture dish treated with $1 \mu \mathrm{M}$ selenoneine. (B) calculated isotope pattern for Se-methylselenoneine, (C) spectrum of Se-methylselenoneine after treatment with selenoneine for $72 \mathrm{~h}$, (D) fragmentation of m/z 292.056; Chromatographic conditions: Column: Atlantis dC18, $4.6 \times 150 \mathrm{~mm}$, column temperature: $30^{\circ} \mathrm{C}$, mobile phase: $20 \mathrm{mM}$ ammonium formate, $3 \%$ methanol $\mathrm{pH} 3.0$, flow rate: $1.0 \mathrm{~mL} \mathrm{~min}^{-1}$, injection volume: $10 \mu \mathrm{L}$. 


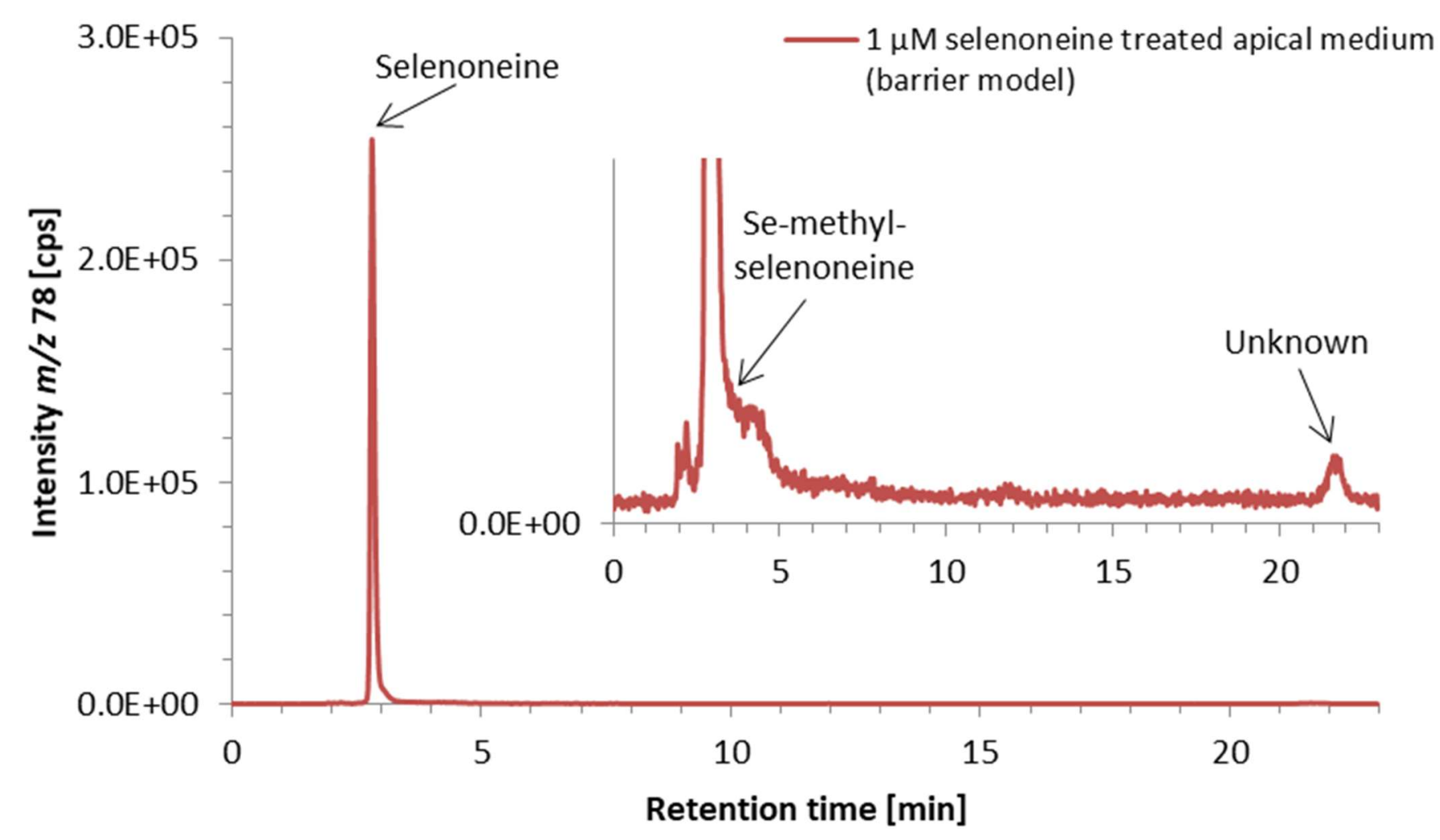

Supplementary Figure S3. RP-HPLC/ICPMS elution profile of a cell culture medium sample (apical) from the Caco-2 intestinal barrier model treated with $1 \mu \mathrm{M}$ selenoneine (incubated on both sides) for $72 \mathrm{~h}$ (red line); column: Atlantis dC18 (4.6 × $150 \mathrm{~mm}$ ), mobile phase: $20 \mathrm{mM}$ ammonium formate, $3 \%$ methanol, pH 3.0, flow rate: $1.0 \mathrm{~mL} \mathrm{~min}{ }^{-1}$, injection volume: $10 \mu \mathrm{L}$. 


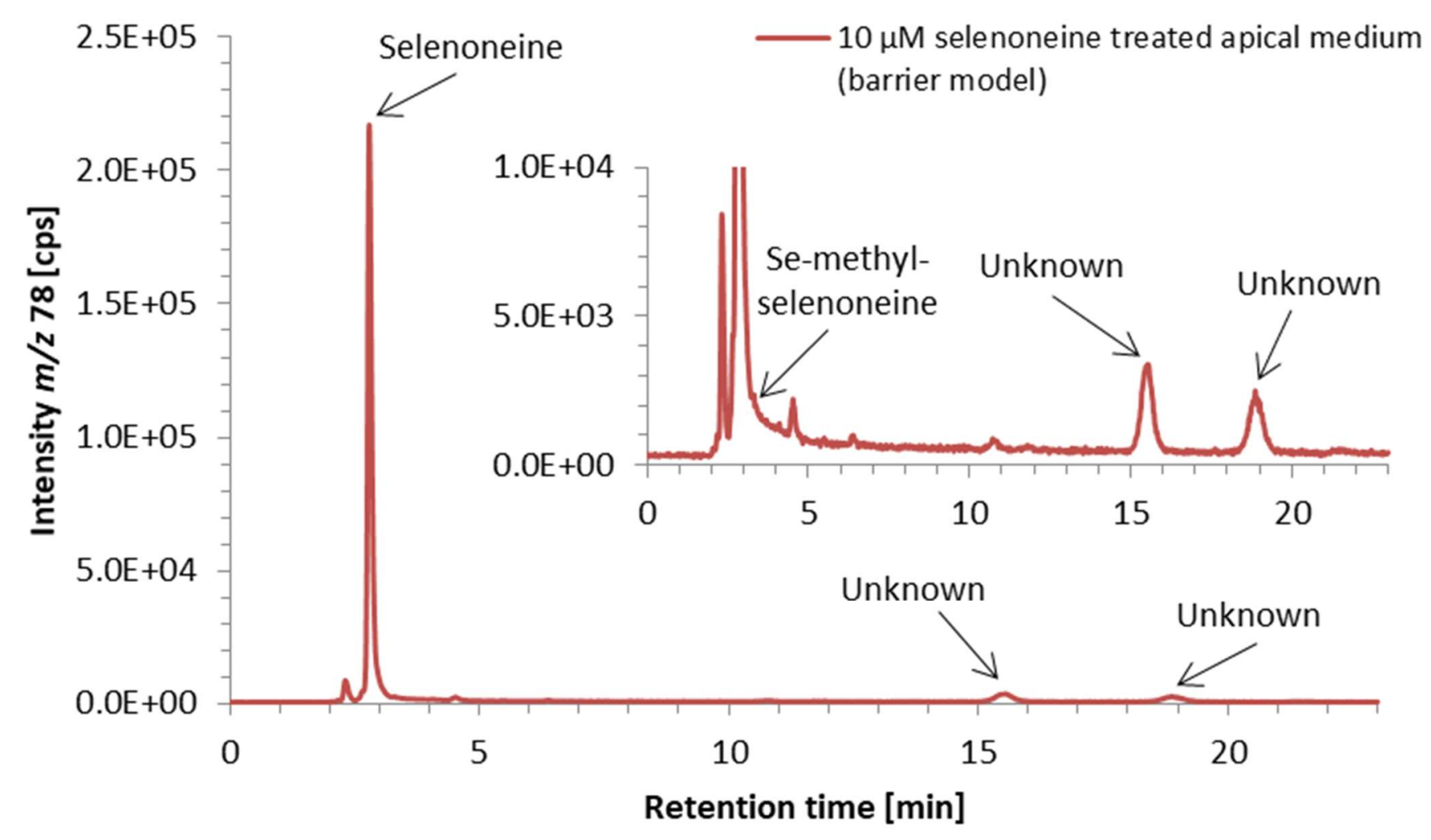

Supplementary Information Figure S4. RP-HPLC/ICPMS elution profile of a cell culture medium sample (apical) from the Caco- 2 intestinal barrier model treated with $10 \mu \mathrm{M}$ selenoneine (incubated on the apical side) for $72 \mathrm{~h}$ (red line); column: Atlantis dC18 $(4.6 \times 150 \mathrm{~mm})$, mobile phase: $20 \mathrm{mM}$ ammonium formate, $3 \%$

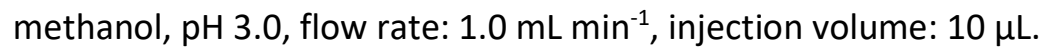

